This item was submitted to Loughborough's Research Repository by the author.

Items in Figshare are protected by copyright, with all rights reserved, unless otherwise indicated.

\title{
The implications of heat electrification on national electrical supply-demand balance under published 2050 energy scenarios
}

PLEASE CITE THE PUBLISHED VERSION

http://dx.doi.org/10.1016/j.energy.2015.11.060

PUBLISHER

(c) Elsevier

VERSION

AM (Accepted Manuscript)

\section{PUBLISHER STATEMENT}

This work is made available according to the conditions of the Creative Commons Attribution-NonCommercialNoDerivatives 4.0 International (CC BY-NC-ND 4.0) licence. Full details of this licence are available at: https://creativecommons.org/licenses/by-nc-nd/4.0/

\section{LICENCE}

CC BY-NC-ND 4.0

\section{REPOSITORY RECORD}

Quiggin, Daniel, and Richard Buswell. 2016. "The Implications of Heat Electrification on National Electrical Supply-demand Balance Under Published 2050 Energy Scenarios". Loughborough University. https://hdl.handle.net/2134/19924. 


\title{
The implications of heat electrification on national electrical supply-demand balance under published 2050 energy scenarios
}

\author{
Daniel Quiggin, Richard Buswell \\ School of Civil and Building Engineering, Loughborough University \\ 01173144657,07793107684 \\ d.quiggin@lboro.ac.uk
}

\begin{abstract}
Published UK 2050 energy scenarios specify a range of decarbonised supply side technologies combined with electrification of transportation and heating. These scenarios are designed to meet $\mathrm{CO}_{2}$ reduction targets whilst maintaining reliability of supply. Current models of the UK energy system either make significant assumptions about the role of demand side management or do not carry out the analysis at sufficient resolution and hence determining the impact of heat electrification on the reliability of supply of the scenarios is not possible. This paper presents a new model that estimates national supply and demand, hour-by-hour. Calculations are based on 11 years of weather data which allows a probabilistic assessment of deficit frequency throughout the day. It is found that achieving demand reduction targets are far more important than meeting electrification targets and that significant adoption of CHP is most likely to deliver a viable energy future for the UK.
\end{abstract}

Keywords: Energy system modelling, Supply - demand grid balancing, Energy scenario, Heat electrification, Climate change, Demand side management 


\section{Introduction}

The energy future of the UK is uncertain. The rising dependency on foreign imports of oil and gas is escalating fears of energy security whilst environmental policy and the Climate Change Act are pushing for changes in the way in which energy services are delivered. A number of energy scenarios that envision the UK's energy infrastructure in 2050 have been published, all of which could potentially meet the UK's commitment to an $80 \%$ reduction in $\mathrm{CO}_{2}$ emissions. Evident in the majority of these scenarios and in the wider political debate, is a growing consensus that electricity will play a central role in the UK energy system of the future [1-7]. Common themes are an increasing proportion of electric vehicles and the replacement of gas driven technologies for heat pumps to provide space heating in buildings, both of which can be decarbonised by deploying other technologies such as solar PV, wind farms and carbon capture and storage (CCS).

A central challenge for these scenarios is the delivery of electrified space heating. Peak heating demands can drive the power supplied by the gas networks up to $300 G W$, six times greater than peak power on the electricity system. Currently gas storage acts as a buffer between supply and demand enabling the gas network to cope with these peaks, an electricity network, however, requires instantaneous supply-demand balancing to avoid blackouts. Only recently has the electrification of heating been considered as having a significant impact on maintaining the security of electrical supply [8] and high resolution modelling techniques are needed to investigate what the implications are for the assumptions on which scenarios are based.

EnergyPlan is a widely used system model, that incorporates transport and heating electrification hour-by-hour and has been applied predominately within Denmark [9-14]. The model has been applied to Estonia, Lithuania and China [15-17], but not the UK. The energy system of Denmark is of a different composition to the UK, apart from the significantly lower electrical demands, $60 \%$ of heating is supplied via district heating and $80.5 \%$ of this heat is produced by Combined Heat and Power (CHP). See Connolly et al. [18] for a review on energy system modelling tools.

High resolution analysis for the UK was conducted by the 'Transition Pathways (TP) to a Low Carbon Electricity Economy' research group using the 'Feasibility of Energy Scenario Assessment' (FESA) model, developed by Barton et al. [19]. FESA is more detailed than the MARket ALlocation model (MARKAL) [20], which considers only 20 approximated 'timeslices' 
within a specific version of MARKAL (Temporal MARKAL) and is one of a minority of energy system models that incorporates transport and heating electrification simultaneously with a variable renewable supply, using a time step of 1 hour.

FESA is driven using 12 months of weather data and assumes households will play a significant role in balancing through demand side management (DSM). A limitation of the model is the assumption that the space heating demand profile over a 24 hour period in all households will be constant (called a 'restricted profile'). This implies that households will be required to heat throughout the day rather than the traditional timing of morning and evening and was treated this way in order to simplify the task of balancing supply and demand [19]. This is a significant assumption which results in the FESA model under-representing peak hourly electrified heating demands and hence is likely to underestimate periods of supply deficit.

In order to evaluate the susceptibility of energy scenarios to supplydemand deficits, a new model called 'Smart Household Energy Demand' (SHED) is presented. Although based on similar modelling principles to that of FESA, SHED does not make any assumptions about the role of future DSM and hence can be used to investigate the implications of space heat electrification on balancing supply and demand by estimating the probabilities of timing and magnitude of deficit periods. The model implements a number of other improvements over those used in FESA, the most notable being the treatment of weather which is extended over 11 years and uses a greater degree of localisation. The paper presents the model and applies it to 6 published UK energy scenarios in order to evaluate the implications of heating electrification on reliability of supply and the role of energy demand reduction in the future.

\section{Selection of energy scenarios}

Energy scenarios are used to map out mixes of different energy supply methods and levels of demand and although it is unlikely that any of these will be realised in the future, they represent options that are able, at least on paper, to deliver the UK's $80 \%$ on $\mathrm{CO}_{2}$ emissions reduction targets. By selecting a number of scenarios to investigate through modelling, a range of heat electrification levels and generation mixes can be explored, allowing more general insights to be gained: 6 published UK scenarios are examined here. 


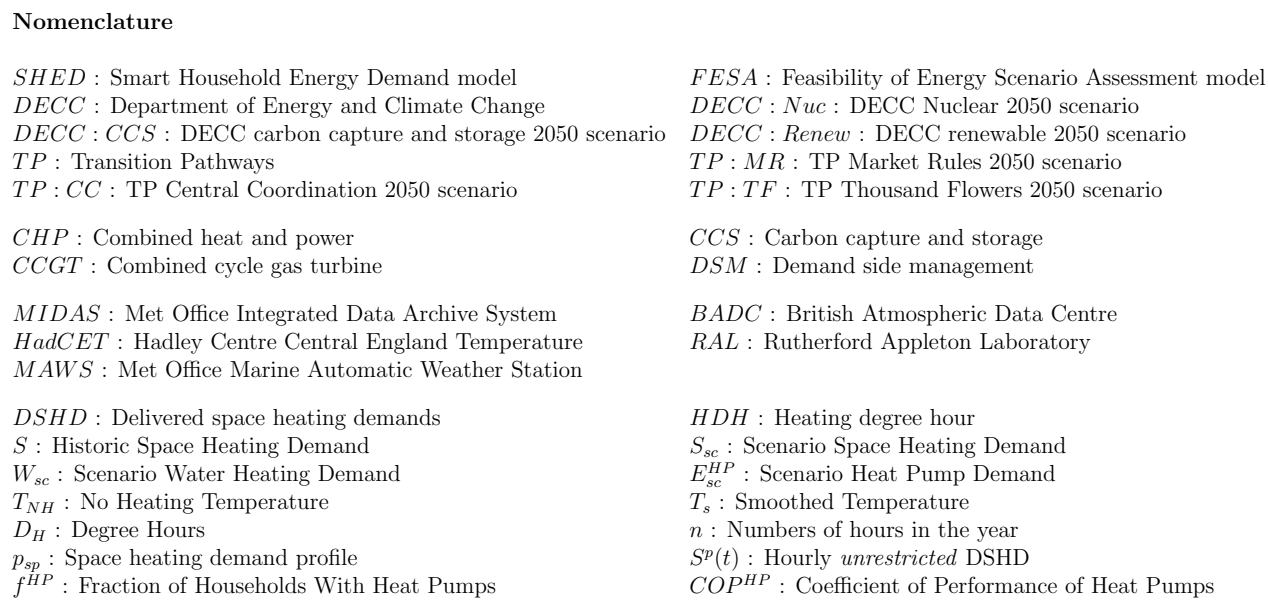

FESA : Feasibility of Energy Scenario Assessment model $D E C C: N u c$ : DECC Nuclear 2050 scenario $D E C C:$ Renew : DECC renewable 2050 scenario $T P: M R$ : TP Market Rules 2050 scenario $T P: T F$ : TP Thousand Flowers 2050 scenario

$C C S$ : Carbon capture and storage

$D S M$ : Demand side management

$B A D C$ : British Atmospheric Data Centre $R A L$ : Rutherford Appleton Laboratory

$H D H$ : Heating degree hour

$S_{s c}$ : Scenario Space Heating Demand

$E_{s c}^{H P}:$ Scenario Heat Pump Demand

$T_{s}$ : Smoothed Temperature

$n$ : Numbers of hours in the year

$S^{p}(t)$ : Hourly unrestricted DSHD

$C O P^{H P}$ : Coefficient of Performance of Heat Pumps

In 2010, the Department of Energy and Climate Change (DECC) published the 2050 Pathways Analysis: 10 of the 16 sub-scenarios specify $\geq 25 \%$ of heating to be electrified and 5 specify $\geq 80 \%$ [5]. 3 of the scenarios describe significantly different futures and are used here in the analysis: "Higher renewables, more energy efficiency", abbreviated here to DECC:Renew; "Higher nuclear, less energy efficiency", DECC:Nuc; and "Higher CCS, more bio energy", DECC:CCS. Research by the Transition Pathways (TP) research group $[1 ; 2]$ developed an alterative set of scenarios, from which the other 3 used in this analysis are taken: a market led pathway, called "Market Rules", $T P: M R$; a government led pathway, "Central Coordination", TP:CC; and a society led pathway, "Thousand Flowers", TP:TF.

Figure 1 compares the annual energy demand in the building related energy categories for each of the 6 scenarios. Note that in the DECC scenarios $48-90 \%$ of heating demand is electrified compared to between $24.5 \%$ in TP:TF and $76.2 \%$ in $T P: C C[3]$.

Figure 2 depicts the generation capacities for each scenario. TP:CC and $T P: M R$ have the greatest diversity in generation, the latter having the greater total capacity of $\sim 163 G W$ due to increased onshore wind, coal (with CCS) and unabated Combined Cycle Gas Turbines (CCGT).

$T P: T F$ is heavily reliant on CHP district heating systems $(52.5 G W)$, which produce power simultaneously with heat: $>70 \%$ of the current in- 


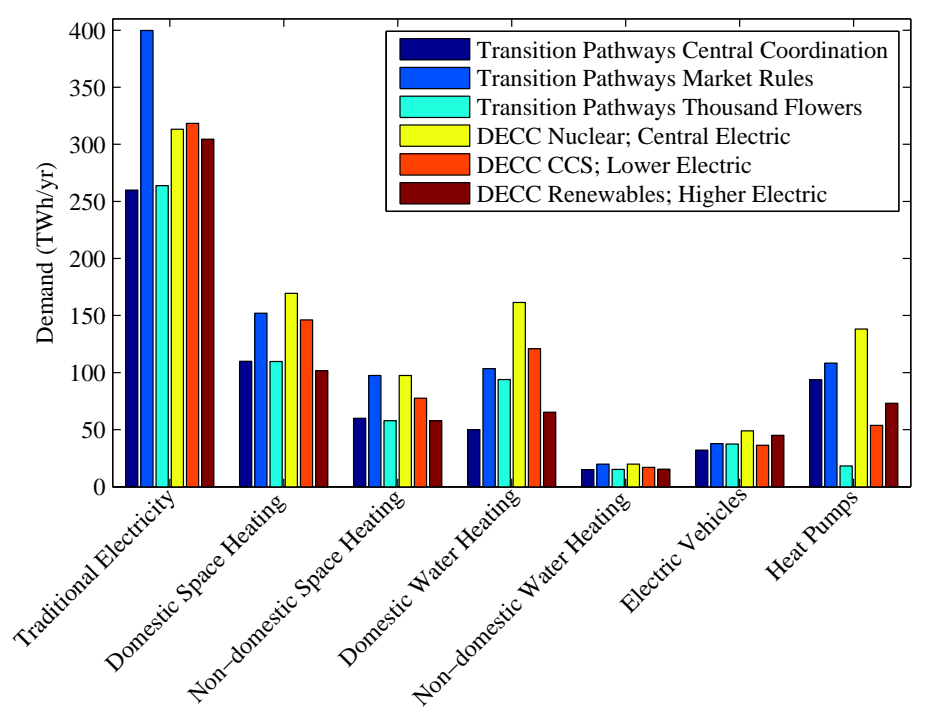

Figure 1: Annual delivered energy demand parameters from each energy scenario $(T W h / y r)$.

stalled generating capacity $(2013,74.7 G W)$. TP:TF also assumes substantial capacity of solar photo-voltaic (PV) and onshore wind generation with a small contribution from dispatchable generators.

$D E C C: N u c$ is dominated by nuclear generation $(75 G W)$, with a small contribution from onshore and offshore wind generation and has the second smallest total generation capacity of $\sim 100 G W$. DECC:CCS assumes the lowest total generation capacity of $\sim 97 G W$, with $\sim 42 G W$ supplied by CCS fitted coal and CCGT generators, the remaining generation capacity is made up of wind, nuclear and hydro. Finally DECC:Renew assumes $\sim 138 G W$ total generation capacity, of which $\sim 82 G W$ is supplied by onshore and offshore wind, $14 G W$ of solar PV and only $14 G W$ of dispatchable generation ( $\sim 10 \%$ of total capacity).

These 6 scenarios represent a broad range of generation capacities and technologies, together with a range of assumptions regarding the electrification of space heating. Throughout the paper, relevant parameters are compared to describe important features of the modelling that underpin the analysis. 


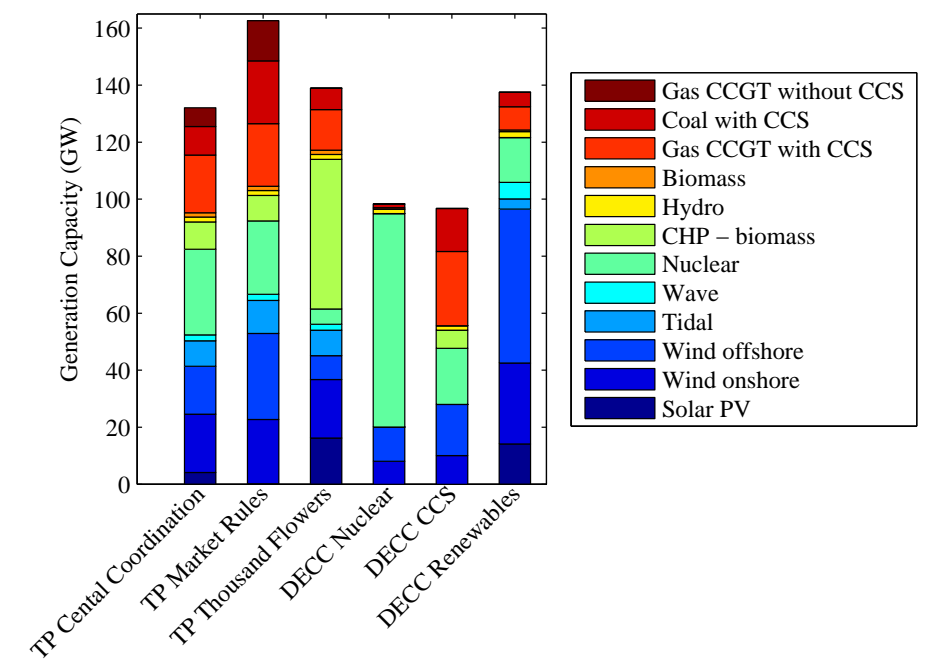

Figure 2: Electricity generation capacity within each of the six scenarios.

\section{Modelling overview}

SHED is a hybrid top-down national supply-demand model with a bottomup household demand and Demand Side Management (DSM) model. This paper describes the top-down component which is used in the analysis presented here. Focus is given to description of the demand modelling, the electrification of heating, in particular. Figure 3 presents an overview of the principle components in the model. The top-down modelling comprises hourly historic weather patterns, demand data and installed generator capacities. Where assumptions are unavoidable, conservative estimates have been applied and hence the results of the analysis should represent the least impact on supply deficit: in essence, a best case scenario.

\subsection{Demand side overview}

Figure 4 illustrates the demand model components and their relationships. Historic national half hourly electricity demand data from ELEXON forms the basis of deriving traditional electricity demands [21]. Traditional electricity demand is the demand arising from both domestic and non-domestic electricity consumers and does not include power for electric vehicles, heat pumps or Economy 7 (resistive space heating). It is the proportion of the 


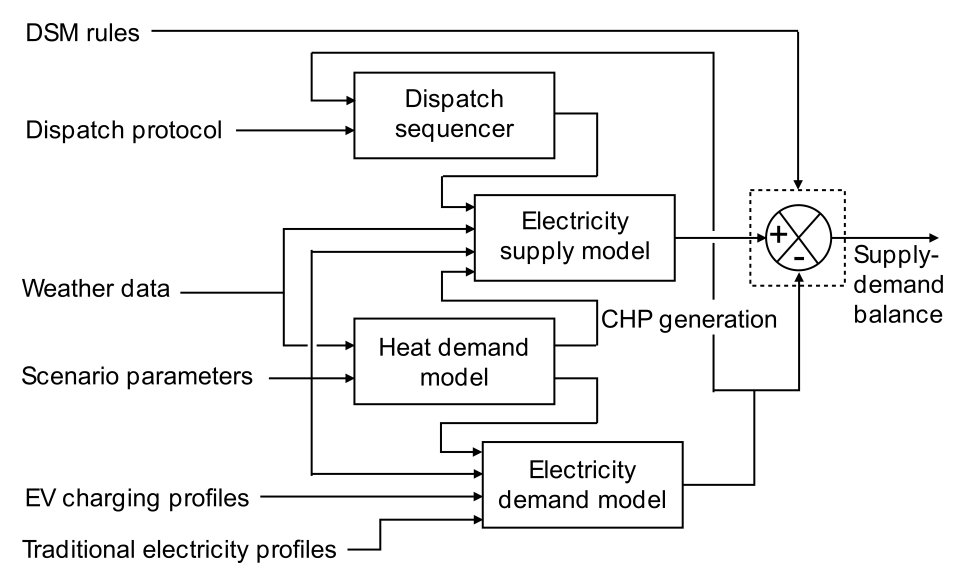

Figure 3: High level schematic of SHED modelling components.

future electrical demand that is similar to that of today. The ELEXON data encompasses all national domestic and non-domestic loads, as well as Economy 7 water and space heating. The energy scenarios specify different levels of Economy 7 and so in the preprocessing of the ELEXON data, this component is removed from the historical data and then re-introduced in the proportions as stipulated in each scenario, scaled by the annual demand.

The model operates on the basis of estimating the hourly delivered space heating demand (DSHD), which is the energy demand at the point of use, rather than the energy in the fuel consumed. Historic hourly temperature data from 3 Met Office Integrated Data Archive System (MIDAS) weather stations form the basis of calculating the number of heating degree hours $(\mathrm{HDH})$, which are scaled by the national annual DSHD as defined in each scenario, to give hourly DSHD.

Hourly delivered water heating demands are calculated, which when combined with hourly DSHD, enable hourly heat pump electricity demands and solar thermal/CHP outputs to be estimated. The solar thermal water heating demands are modelled first, such that heat pumps follow a reduced net heating demand. Electric vehicle (EV) charging profiles [22] are utilised to derive the scenario specific EV hourly demands. Finally the resistive heating demands are calculated utilising current Economy 7 water and space heating profiles.

The final hourly electricity demand becomes the sum of traditional electricity, electrical vehicle, heat pump and resistive heating demands within 
both domestic and non-domestic sectors. Details of the parameters in these models can be found in the literature of the scenarios $[3 ; 19 ; 23]$.

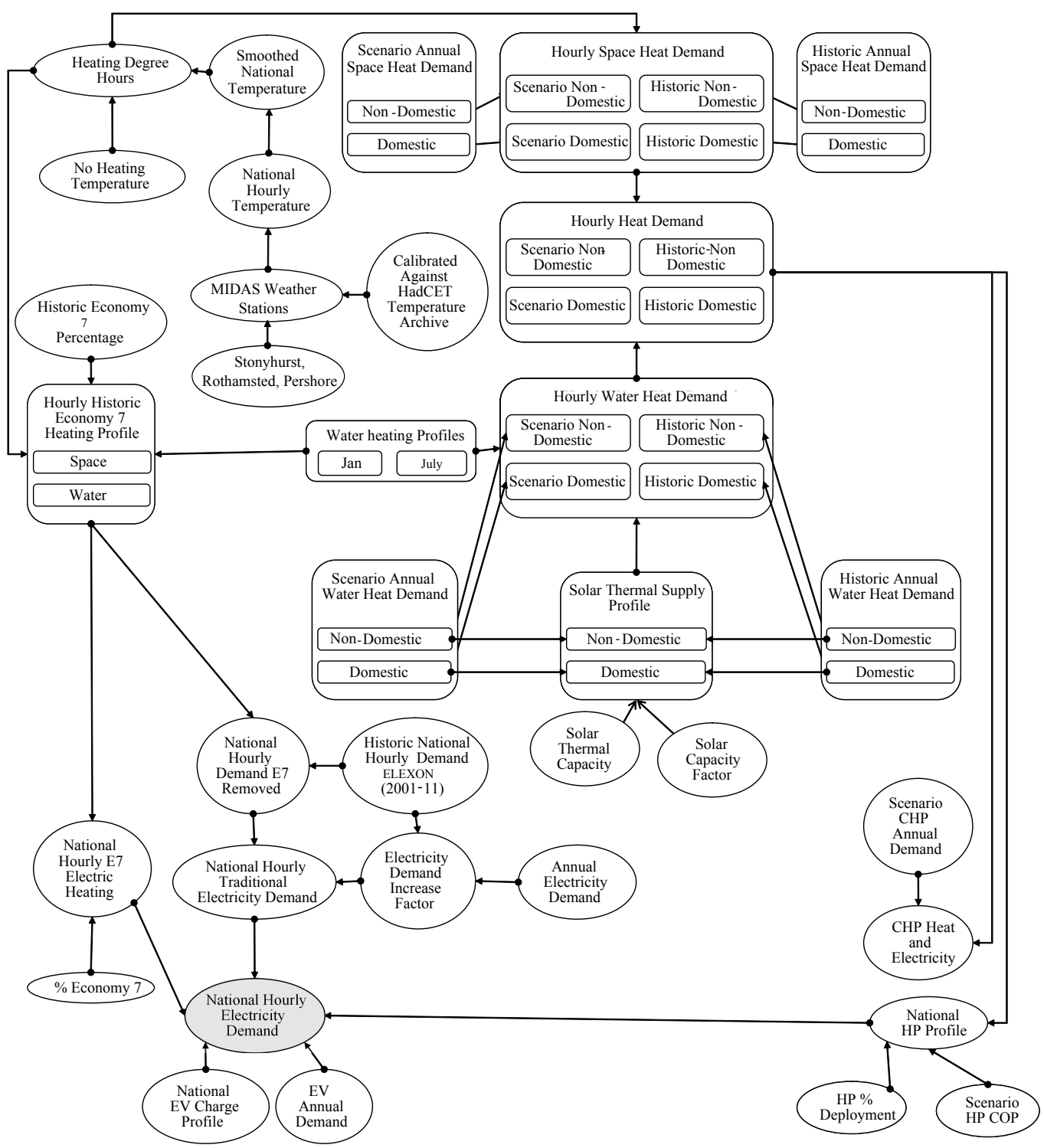

Figure 4: Detailed representation of the components of the demand model elements of SHED. Target output highlighted in grey. HP = heat pump, EV = electric vehicle, $\mathrm{E} 7=$ Economy 7. 


\subsection{Supply side overview}

In order to model electricity generation, there needs to be a dispatch protocol to sequence when generators come on and off line. SHED implements a simplified protocol which assumes the overriding objective governing generator dispatch is the minimisation of $\mathrm{CO}_{2}$ emissions. Under this assumption renewable generators are left to generate uncurtailed as are CHP generators, albeit that these follow the demand for heat. Post these non-dispatchable generators, pumped storage and inter-connectors are dispatched prior to the dispatchable generators. Finally non-domestic and then domestic DSM are introduced as the penultimate and final balancing mechanisms respectively.

The renewables modelled include; wave, solar PV, tidal stream, onshore and offshore wind and for each, hourly supply modelling is composed of:

- historic weather data;

- the specific technology characteristics; and,

- sub-division of the country into weighted regions.

From these, hourly national capacity factors are calculated. A capacity factor is the ratio between an electrical generators actual output over a given period of time, to the potential output of that generator if it were able to operate at its rated nameplate generation capacity. The national generator capacities are combined with these capacity factors to form the hourly renewable generation, which is implemented for each scenario. The weightings between UK sub-regions are based on the total possible available resource, which originate from UK government estimates [24]. The hourly weather data used to model the renewable generation was obtained from the British Atmospheric Data Centre (BADC) [25] with the exception of wave data, which was obtained from the Met Office [26].

\section{Heating demands}

Wilson et al. investigated historic daily gas demands and found that even electrifying $30 \%$ of the non-daily metered heating requirement via heat pumps in the UK would increase daily demand by $\sim 25 \%$, in addition to the total national electrical demand becoming more variable [8]. The work concluded that instantaneous demands would be higher than daily demands, increasing peak demand. Table 1 details the key parameters that relate to 
the provision of heating for each scenario. The average proportion of heat demand delivered by heat pumps is $67.3 \%$ with a maximum of $90 \%$ in the DECC:Renew scenario; given the findings of Wilson et al [8] these levels of heating electrification are almost certain to be problematic. Achieving the delivered heating demand reduction targets in each scenario, therefore, becomes a critical assumption when estimating potential supply deficits.

Table 1: Key heating demand parameters for each energy scenario.

\begin{tabular}{|c|c|c|c|c|c|c|}
\hline & TP:CC & TP:MR & TP:TF & DECC:Nuc & DECC:CCS & DECC:Renew \\
\hline Households (million) & 35.6 & 35.6 & 35.6 & 40.0 & 40.0 & 40.0 \\
\hline Households with & & & & & & \\
\hline solar thermal $(\%)$ & 27.8 & 0 & 83.5 & 0 & 0 & 2.3 \\
\hline $\begin{array}{l}\text { Heat supplied by } \\
\text { resistive heating (\%) }\end{array}$ & 0.01 & 0.01 & 0.01 & 0 & 0 & 10 \\
\hline heat pumps (\%) & 76.2 & 77.1 & 24.5 & 88.0 & 48.0 & 90.0 \\
\hline Assumed heat pump COP & 2.65 & 2.65 & 3 & 2.85 & 3.23 & 2.94 \\
\hline
\end{tabular}

\subsection{Heating demand reduction targets}

Historic levels of annual-delivered heating demands have not been published, papers and government statistics quote energy demand by fuel type, hence historic delivered heating demands need to be derived. The delivered energy end use by fuel type, data on conversion technologies at point of use, and corresponding technologies efficiencies were obtained from the UK government [27]. Standard and Combination boilers are assumed to run at $76 \%$ efficiency, with condensing and condensing combination boilers at 91\%. The average domestic DSHD between 2001 and 2011 is $257 T W h / y$, and $67 T W h / y$ for water heating.

Table 2 gives the percentage change in DSHD implied by each scenario, relative to the average 2001-2011 value. In the domestic sector the average DSHD across the scenarios is $135 T W h / y$, representing a $47.5 \%$ reduction relative to historic values. The reductions are most challenging in TP:TF and DECC:Renew, at $57.3 \%$ and $60.4 \%$ respectively. Across the eleven years of historic data, an average total delivered heating demand of $429.1 T \mathrm{Wh} / \mathrm{y}$ is found, this includes the non-domestic sector and implies an average reduction of $20.5 \%$ across the scenarios. 
Table 2: Scenario heating demands and implied reductions relative to historic mean demands $(T W h / y r)$.

\begin{tabular}{lcccccc} 
& TP:CC & TP:MR & TP:TF & DECC:Nuc & DECC:CCS & DECC:Renew \\
\hline Domestic space heating & 129.6 & 152.0 & 109.7 & 169.5 & 146.2 & 101.8 \\
\% change on historic & -49.6 & -40.9 & -57.3 & -34.1 & -43.1 & -60.4 \\
Non-domestic space heating & 97.4 & 97.4 & 57.8 & 97.5 & 77.6 & 57.8 \\
Domestic water heating & 97.63 & 103.58 & 94.01 & 161.42 & 120.9 & 65.26 \\
Non-domestic water heating & 19.78 & 19.78 & 15.26 & 19.8 & 17.04 & 15.3 \\
Total heating demand & 344.4 & 372.8 & 276.7 & 448.2 & 361.7 & 240.2 \\
\% change on historic & -19.7 & -13.1 & -35.5 & +4.5 & -15.7 & -44.0 \\
\hline
\end{tabular}

\subsection{Modelling hourly delivered heating demands}

In order to estimate the electrified heating demands in each scenario, the delivered heating demands need to be estimated based on historical data. These comprise of both domestic and non-domestic water and space heating. The unrestricted (twin peak) demand profiles used in this work originate from heat flow measurements in a district heating scheme of a social housing complex [28]. Normalised profiles for space and water heating are shown in Figure 5. Note that $8.4 \%$ of the total daily space heating demand occurs at $8 \mathrm{am}$, forming the dominant morning peak period. Hourly national water heating demands are derived from the 24 hour profile (Figure 5(a)) scaled by the scenario annual target (Table 2) and stretched out over the year.

The unrestricted space heating profile (Figure 5) is applied only to the domestic sector, the non-domestic sector is assumed to follow a flat heating profile. Hourly temperature data forms the basis of calculating the number of heating degree hours (HDH) which are used to derive hourly DSHD. A Heating Degree Hour is the number of degrees celsius by which the hourly average outside temperature is below a no heating temperature, $T_{N H}$, and is the temperature at which no heating is required to maintain sufficient inside temperature, and is dependent on; building characteristics, heating equipment used, number of occupants and their behaviour. $T_{N H}$ is assumed to be $15.5^{\circ} \mathrm{C}$, as used within other studies. The smoothed temperature, $T_{s}(t)$, given by the moving average (Equation 1) is taken as the outside ambient temperature from which the number of $\mathrm{HDH}, D_{H}$, is found (Equation 2). This is the difference between the smoothed temperature and the no heating temperature, where $D_{H}$ is zero if $T_{s}$ is greater than $T_{N H}$. 


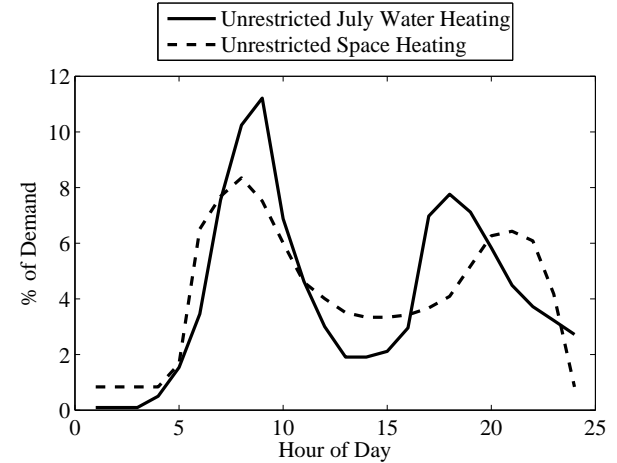

(a) Unrestricted heat demand profiles. Source : Woods and Dickson [28].

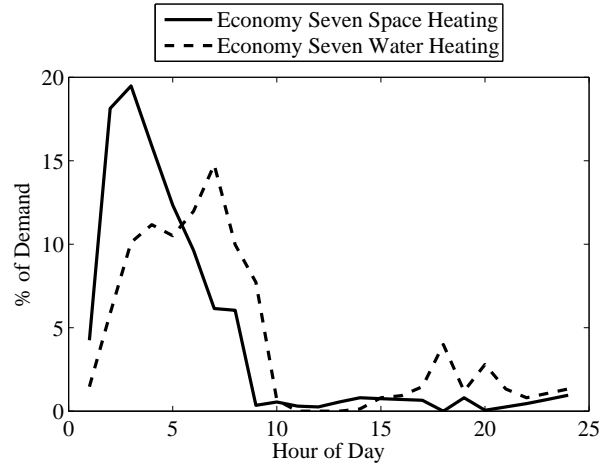

(b) Economy 7 heat demand profiles.

Figure 5: Heat demand profiles: percentage of demand occurring each hour of a typical day.

$$
T_{s}(t)=\sum_{t-23}^{t} \frac{T(t)}{24}
$$

where; $T(t)$ is the hourly outside ambient temperature

$$
D_{H}(t)= \begin{cases}T_{N H}-T_{s}(t) & \text { if } T_{N H}>T_{s}(t) \\ 0 & \text { if } T_{N H} \leq T_{s}(t)\end{cases}
$$

The majority of UK housing, commerce, and industry is located in England. The method of using an area enclosing the majority of the building stock is common within representative temperature measurements [29]. The daily Hadley Centre Central England Temperature (HadCET) record is representative of a triangular area enclosed by Lancashire, London and Bristol [29]. As hourly, rather than daily mean temperatures are required, HadCET is insufficient for the purposes of SHED. FESA utilised the Rutherford Appleton Laboratory (RAL) dataset in Oxfordshire to derive hourly values, and calibrated the data against HadCET. Figure 6 shows the first 10 days of external temperatures for both SHED and FESA, alongside the HadCET temperatures. The differences between SHED and FESA temperatures arise from SHED utilising three MIDAS weather stations close to the points of the 
HadCET triangle, whereas FESA utilises data from one station at RAL.

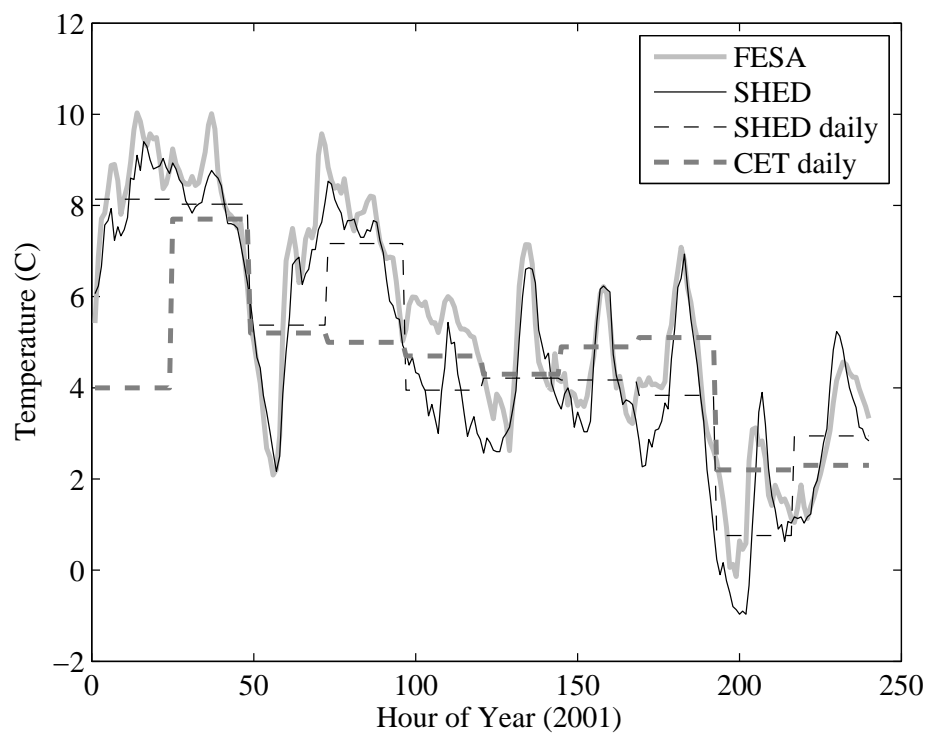

Figure 6: Comparison of SHED to FESA and CET daily temperatures. (CET - Central England Temperature record).

Hourly DSHD, $S(t)$, is the product of the annual DSHD $(S)$ and the $\mathrm{HDH}$, normalised by the total number of HDH in the year. Equation 3 gives the hourly flat (or restricted) DSHD.

$$
S(t)=S \cdot \frac{D_{H}(t)}{\sum_{1}^{n} D_{H}(t)}
$$

where; $S(t)$ is the hourly flat DSHD;

$S$ is the annual delivered space heating annual demand;

$D_{H}(t)$ is the number of degree hours; and,

$n$ is the numbers of hours in the year.

To account for the daily unrestricted heating profile the total flat DSHD each day is redistributed across the 24 hours by the proportions of demand for reach hour described by the unrestricted profile. The resulting unrestricted demand profile is given by Equation 4. The hourly flat (or restricted) DSHD 
is used to determine non-domestic hourly heating demands.

$$
S^{p}(t)=\sum_{1}^{24} S(t) \cdot \frac{p_{s p}(t)}{\sum_{1}^{24} p_{s p}(t)}
$$

where; $S^{p}(t)$ is the hourly unrestricted DSHD;

$p_{s p}$ is the space heating demand profile of Figure 5; and, $S(t)$ is the hourly flat DSHD of Equation 3.

\subsection{Deriving hourly delivered heating demands}

Historic peak hourly DSHD for the flat and unrestricted heating profiles are $153.9 G \mathrm{~W}$ and $299.9 G W$ respectively, when averaged across the eleven years of data. Peak hourly DSHD for each scenario, under the unrestricted and flat heating profiles are given in Table 3, together with the implied reductions relative to historic peak values. The average reduction in peak demand across all scenarios, relative to historic peak demands for the flat and unrestricted demand profiles are $42.9 \%$ and $42.1 \%$ respectively. The unrestricted heating profile results in peak DSHD almost twice that of the flat (or restricted) profile.

Table 3: Scenario peak delivered space heating demands under the flat and unrestricted profiles and associated reductions relative to historic peak demands.

\begin{tabular}{cccccc} 
TP:CC & TP:MR & TP:TF & DECC:Nuc & DECC:CCS & DECC:Renew \\
\hline 92.5 & 101.6 & 68.2 & 108.8 & 91.1 & 65.0 \\
-39.9 & -34.0 & -55.7 & -29.3 & -40.8 & -57.7 \\
182.7 & 200.7 & 134.8 & 214.9 & 180.0 & 128.4 \\
-39.1 & -33.1 & -55.1 & -28.4 & -40.0 & -57.2
\end{tabular}

\section{Electrical supply-demand modelling}

\subsection{Demand side}

The first step in modelling the hour-by-hour electricity demand is to remove Economy 7 demand from the historic demands in order to obtain the traditional electricity demand. Removing Economy 7 space and water 
heating has a significant impact on traditional electricity demand across the year since at 03:00 hours, Economy 7 equates to 59\% of national demand. As demonstrated in Figure $7(\mathrm{a}-\mathrm{b})$, the peak demand remains roughly equivalent between pre and post Economy 7 removal at $\sim 50-58 G W$. Whereas the minimum demand drops to $\sim 15 G W$, from $\sim 22 G W$.

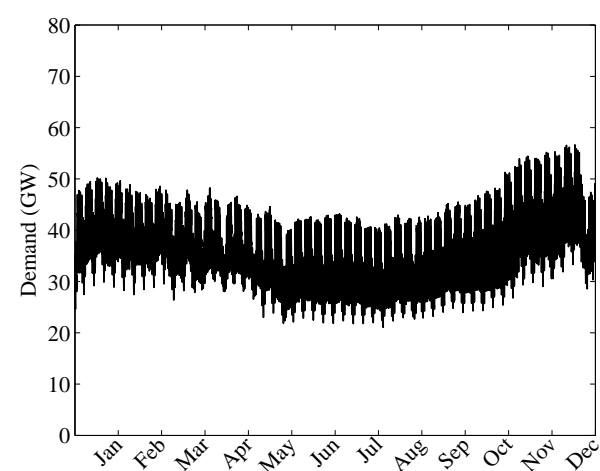

(a) Historic Elexon data.

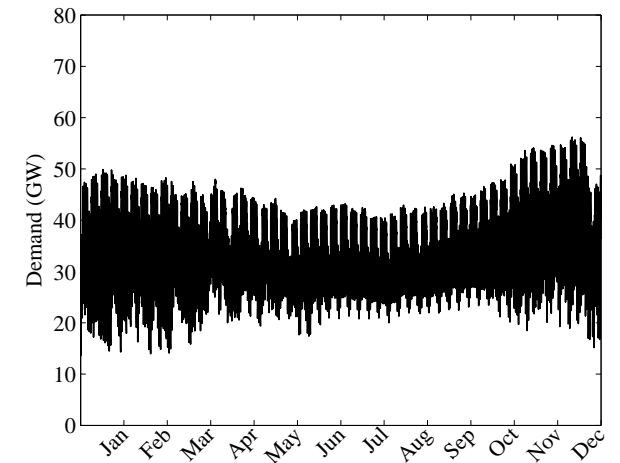

(b) Traditional electricity demand : historic Elexon data with Economy 7 space and water heating removed.

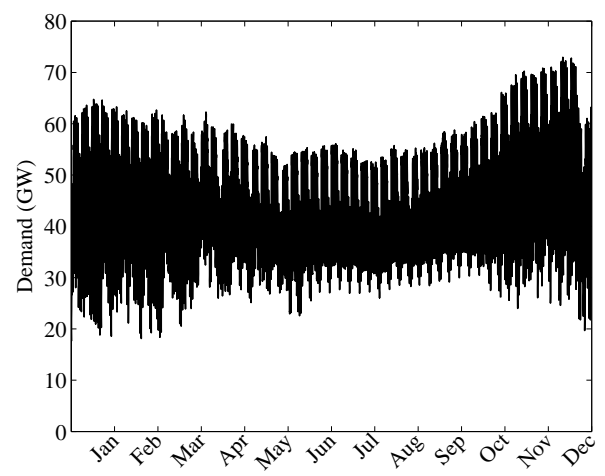

(c) TP Market Rules traditional electricity demand.

Figure 7: Hourly traditional electricity demand with Economy 7 demand removed. 2001 data.

Heat pump demand $\left(E_{s c}^{H P}(t)\right)$ is modelled to follow space and water heating demands, although the heat pumps are not designed to follow variable load patterns. Equation 5 describes how heat pump electrical demand is calculated. 


$$
E_{s c}^{H P}(t)=\left(S_{s c}(t)+W_{s c}(t)\right) \cdot f^{H P} / C O P^{H P}
$$

where; $S_{s c}(t)$ is scenario hourly space heating demand - given either by $S^{p}(t)$ or $S(t)$, depending or the utilisation or not of the unrestricted heating profile; $W_{s c}(t)$ is the scenario hourly water heating demand; $f^{H P}$ is the scenario defined fraction of heat supplied by heat pumps, and; $C O P^{H P}$ the coefficient of performance of the heat pumps.

When the flat (or restricted) heat demand profile is utilised, SHED and FESA find an equivalent peak heat pump demand of $34.5 G W$ (for TP Market Rules), under 2001 data. Applying the unrestricted domestic heating profile, this value increases by $60.7 \%$ to $56.8 G W$. Annual and peak demands for unrestricted and flat profiles under each scenario, are given in Table 4 . The first 24 hours of heat pump demand under TP:MR are illustrated in Figure 8(a). The morning and evening peaks under the flat profile result from the unrestricted water heating profile. The unrestricted profile results in the peak hourly heat pump demand increasing by $\sim 50 \%$.

Table 4: Scenario annual and peak heat pump demand under the flat and unrestricted profiles.

\begin{tabular}{lcccccc} 
& TP:CC & TP:MR & TP:TF & DECC:Nuc & DECC:CCS & DECC:Renew \\
\hline Annual $(T W h / y r)$ & 93.9 & 108.4 & 18.3 & 138.2 & 53.7 & 73.1 \\
Flat Peak $(G W)$ & 30.9 & 34.5 & 6.8 & 43.8 & 17.0 & 23.2 \\
Unrestricted Peak $(G W)$ & 51.0 & 56.8 & 10.9 & 68.8 & 27.2 & 38.3 \\
\hline
\end{tabular}

Although a number of studies have suggested that EVs could be capable of providing power back to the grid, indications are that this is likely to be expensive [30]. In this work, it is assumed that EVs will not provide grid balancing. The driving and charging profile used to model hourly EV demands is based on a modified DSM profile given in [22], and depicted in Figure 8(b). Resistive heating is negligible in all scenarios with peaks less 

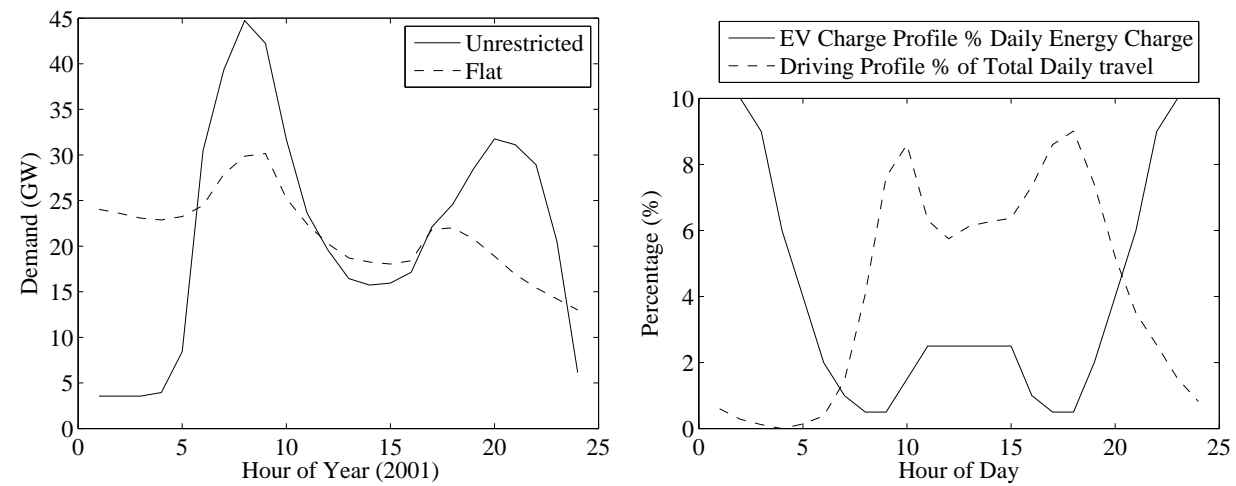

(a) First 24 hours of heat pump demand (b) Electric vehicle charging and driving under the unrestricted and flat space profile. Source : [22].

heating demand profiles of the TP Mar-

ket Rules scenario.

Figure 8: Demand profiles

than $35 M W$, apart from in DECC:Renew where $10 \%$ of delivered heating demand is provided by resistive heating, resulting in $27.8 \mathrm{GW}$ additional peak demand.

The electricity system is considered as a single node, as such transmission and distribution losses are accounted for by a simple increase of $7 \%$, regardless of local generation levels but assuming a small increased efficiency of the electrical network by 2050. These losses are applied to the total electrical demands.

\subsection{Supply side}

The generation mixes of the six modelled scenarios were given in Figure 2 and do not include availability factors, which account for the amount of time that a generator is available for dispatch.

SHED uses 11 years of weather data, from a large number of weather stations, many of which had to be removed due to poor data quality. The criteria for inclusion was that $\leq 95 \%$ of the data required no algorithmic correction, and that no more than four consecutive days were missing.

Wave capacity factors are calculated from wave height and period, at five locations, using the Met Office Marine Automatic Weather Station (MAWS) network [26] (locations detailled in Quiggin [31]). The hourly average capacity factor for the eleven years of data is $21.1 \%$. 
Solar PV capacity factors are calculated using hourly global irradiation data from 32 Met Office weather stations [25], for (locations detailled in Quiggin [31]). It is assumed the majority of installations are roof mounted. UK sub regions are weighted by urban area distributions obtained from the Department for the Environment Food and Rural Affairs [32] and The Office for the Deputy Prime Minister [33] (ODPM). A linear relationship between solar irradiance and PV generation is assumed: the ratio between hourly regional irradiance and the $1,000 \mathrm{~W} / \mathrm{m}^{2}$ test conditions of nameplate rated panels. This does not account for inverter efficiencies or domestic line losses. No correction was made for angle of inclination as the DTI report, upon which resource estimates are based (see section 3.2), assumes solar PV installations will be installed facing a range of different orientations [24]. The average capacity factor for the eleven years of data is found to be $11.4 \%$.

Of all the renewable generation technologies within the modelled scenarios, wind generation has the greatest variability of output [3]. For both onshore and offshore wind generation capacity factors, the hourly wind power generated is normalised by the installed capacity, based on resource estimates from the aforementioned DTI report [24]. For onshore, this results in preference towards Scotland, hence there is a regional subdivision around Scotland. For offshore wind, this weighting results in a preference towards areas with accessible sea bed depths. A mixture of coastal and inland sites were used for onshore. Due to a lack of offshore wind speed measurements, wind speeds have been calculated using onshore coastal weather stations, and corrected using the empirical linear regression relationship from Hsu [34]. Hourly wind speeds are converted into power generation using generic wind power curves for $2 M W$ and $5 M W$ turbines, originating from RE Power Systems [35] turbine data. Wind weather station locations and regional sub divisions are detailled in Quiggin [31]. A more accurate method of determining high temporal wind generation would involve utilising empirical wind farm data, as is achieved by Lund [11] within Denmark, under the EnergyPlan model framework. Within the UK this is challenging due to availability of data, and geographic wind farm coverage not representing the total possible wind resource.

The mean hourly capacity factors for onshore and offshore wind generation are $30.1 \%$ and $44.3 \%$ respectively, over the 11 years of weather data. For the 2001 data, FESA yields capacity factors of $29.3 \%$ and $42.8 \%$ for onshore and offshore respectively, while SHED yields $28.3 \%$ and $42.7 \%$.

Tidal generation is calculated in a similar method to Mackay [36], where 
output is proportional to the tidal stream velocity cubed, on a lunar cycle of 29.5 days, generating power on both the ebb and flow tides. It is assumed there is one main scheme such as the proposed Bristol Channel scheme [37], resulting in four distinct peaks in generation per 25 hour period. Across the eleven years of SHED the average capacity factor is found to be $24.4 \%$.

CHP units are treated as district heating systems, due to the high capital costs of the units [38] and are modelled to follow heating demand. Due to capacity and availability constraints, the units do not always meet the hourly heating supply targets specified by the scenarios.

\subsection{Balancing Mechanisms}

The scenarios investigated with SHED involve a limited number of balancing mechanisms. On a national level these include pumped storage and interconnectors, invoked prior to dispatchable generators, due their low emission intensity factors. Both act to smooth the net demand, this is the demand following non-dispatchable (renewable) generation has reduced the initial demand.

Other balancing mechanisms are possible, such as:

- decentralised and centralised battery storage;

- hydrogen production by electrolysis during surplus periods;

- vehicle-to-grid technologies (V2G);

- switching plug-in hybrid electric vehicles (PHEVs) to run only from fuel at times of low supply and high demand; and,

- allowing the dispatch of CHP units to follow electrical (rather then heat) demands, this would however be economically sub-optimal and potentially expensive.

All scenarios utilise synthesised hydrogen for hydrogen vehicles. In the SHED model, periods of surplus are only used to balance national deficit hours, if the surplus hour falls within a DSM window, either side of a deficit period. DSM is discussed in Section 5.5.

Interconnectors follow the net demand post pumped storage, hourly imports and exports are limited by the interconnector capacity limit, as given in Table 5 , and weighted by the yearly maximum net demand. This results 
in greater imports during periods of greater potential deficit. Post interconnectors and pumped storage the average standard deviation in net demand, across the six scenarios falls from $14.39 G W$ to $11.10 G W$. This reduced net demand variation reduces the reliance on higher emission generators, and enables increased load factors as peak demand is reduced.

Previous studies [12] that have investigated the possibility of integrating high penetrations of wind have found that ensuring CHP units are included in regulated electrical dispatch, and combined with heat pumps, is integral in avoiding periods of severe excess supply.

Table 5: Scenario national balancing mechanisms.

TP:CC TP:MR TP:TF DECC:Nuc DECC:CCS DECC:Renew

\begin{tabular}{lcccccc}
\hline PS Store Cap (GWh) & 25 & 25 & 25 & 30 & 30 & 400 \\
PS Generation Cap (GW) & 3 & 3 & 3 & 1.22 & 1.22 & 17.22 \\
IC Cap (GW) & 6.81 & 6.81 & 6.81 & 10 & 10 & 30 \\
\hline
\end{tabular}

\subsection{Dispatchable generators}

Dispatchable generators are divided into tier 1 and tier 2 generators, dispatched in response to the smoothed net demand, after pumped storage and interconnectors have been dispatched. Each generator within each tier has an equal share of dispatch within that hour. The load duration curves given in Figure 9 show the duration for which the dispatchable generators are operating at part to full loading, running SHED over the 11 years of data. Mean load factors across the scenarios range between $0.39-0.63$. These load factors compare to historic values of 0.71 in 1996 and 0.48 in 2011, both for CCGTs [39].

A proportion of nuclear generation is considered to run during all hours, and thus is considered to be non-dispatchable. Under current European Utilities Requirements, nuclear power stations must be able to cycle daily between $50-100 \%$ of their rated power, with ramp rates between $3-5 \%$. As the Nuclear Energy Agency OECD [40] point out, the current lack of nuclear plant load following is an economic rather than technical barrier. $60 \%$ of nuclear generation is considered dispatchable in SHED which is an optimistic assumption. 


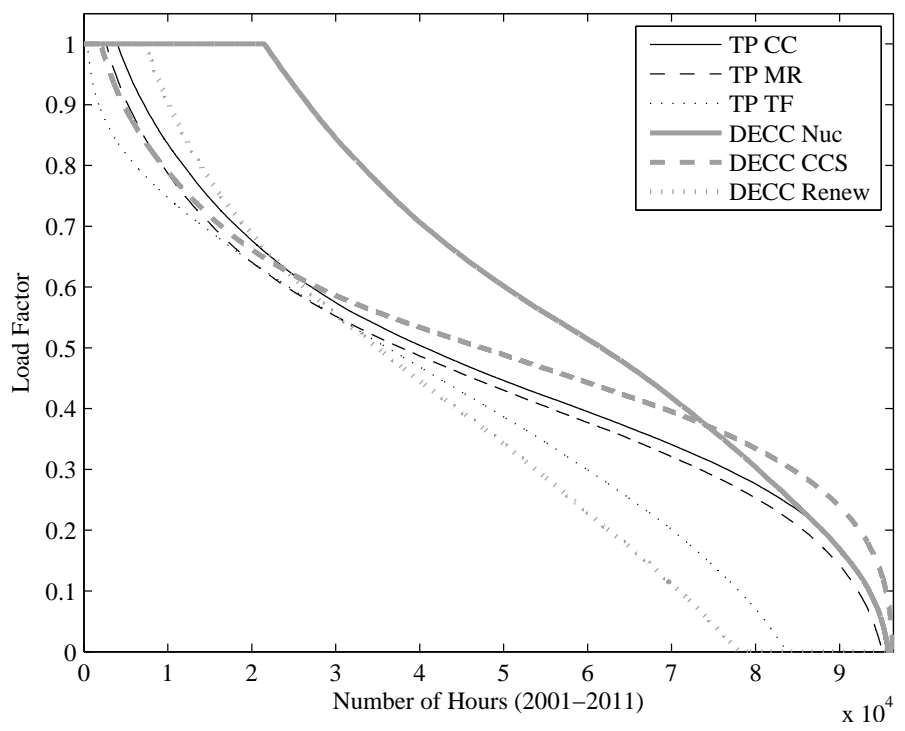

Figure 9: Scenario load duration curves for all dispatchable generators for 2001 - 2011 data.

\subsection{Demand side management}

Neither the TP or DECC scenarios quantify the frequency and magnitude of DSM participation. The DECC scenarios place a significant emphasis on DSM, assuming $20-30 \%$ of demand can be shifted in time [5]. The DSM periods are those instances where DSM is required to prevent demand exceeding supply, and is sequentially the last component treated in the model. The DSM algorithm structure is laid out in Figure 10. In reality, DSM will also encourage households to shift demand to minimise peaks, and hence increase load factors on dispatchable generators.

An Ofgem [41] report has been used to define non-domestic DSM dynamics beyond the generalised algorithm in Figure 10. The moderate Ofgem scenario was followed, defining the winter weekday load flexibility during peak demand as $2.5 G W$, representing $17 \%$ of current non-domestic demand. Peak non-domestic demand currently occurs at $\sim 11 \mathrm{am}$. Within SHED the $2.5 G W$ demand flexibility is available during all periods of peak demand, where peak is defined as occurring when demand is greater than the average yearly demand. This is based on an assessment that greater smart metering control capabilities will be available by 2050 . 


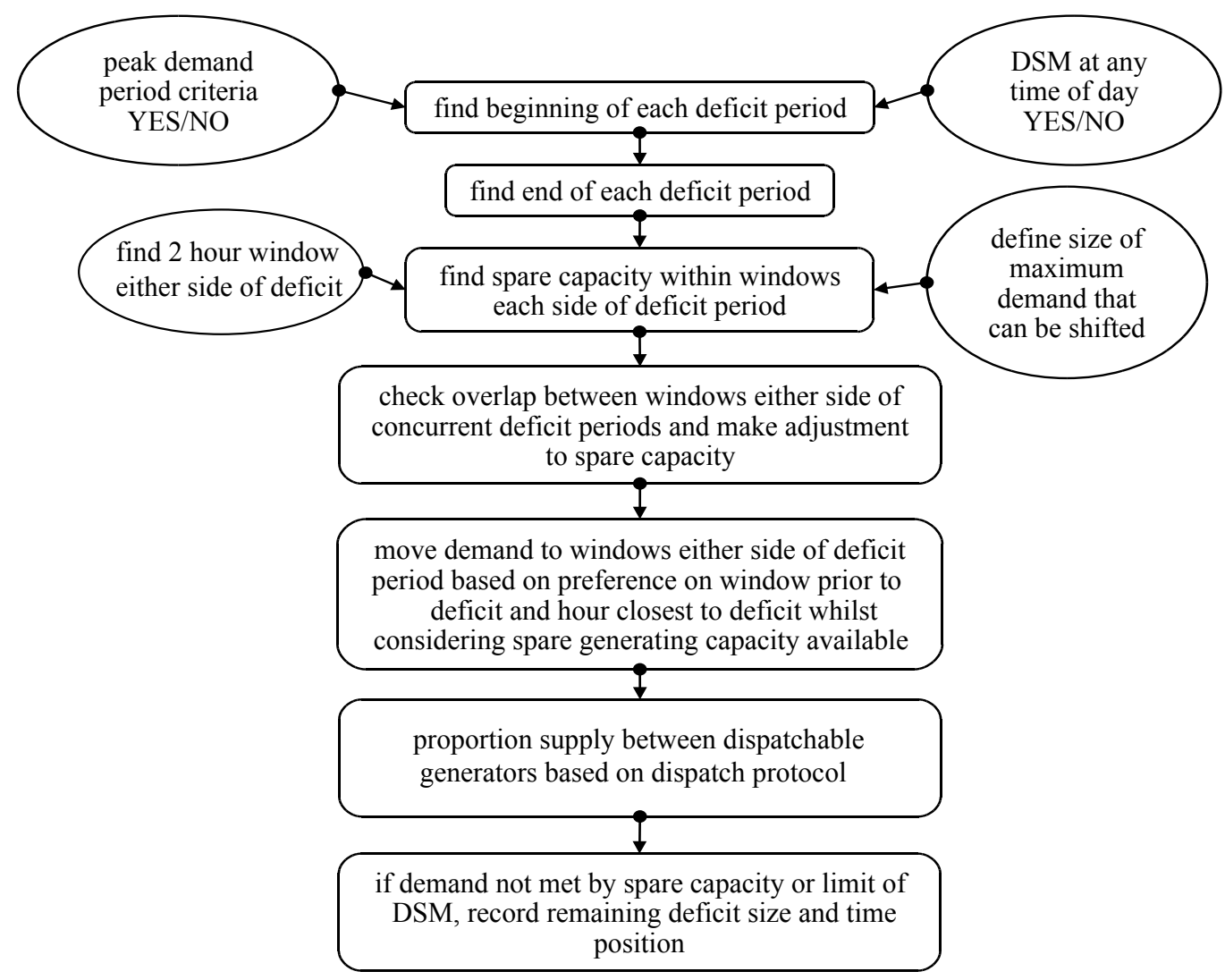

Figure 10: Representation of the generalised DSM algorithm for domestic and nondomestic consumers.

The domestic DSM algorithm allows participation during any hour of the day, with no maximum constraint. The time window within which demand must be shifted to, is kept to 2 hours pre and post the deficit period. Spare capacity within that window must exist to supply the demand. Within the non-domestic DSM algorithm, the demand is removed in equal proportions within the hours of the deficit, whereas within the domestic DSM algorithm the largest deficit is given priority. As the $2.5 G W$ maximum demand constraint is removed, the only constraining factor to unlimited demand reduction is the spare capacity and surplus renewable supply, within the 2 hour window, either side of the deficit period.

It should be noted that electrified heating demand can only be shifted forward in time with the aid of storage or highly heat efficient homes, whereas 
traditional electricity can be shifted forwards or backwards in time.

Table 6: Scenario average annual deficits and domestic DSM contribution to reduce those deficits.

\begin{tabular}{lcccccc} 
& TP:CC & TP:MR & TP:TF & DECC:Nuc & DECC:CCS & DECC:Renew \\
\hline Av Ann Deficit $(T W h / y)$ & 2.05 & 1.45 & 0.01 & 22.69 & 0.51 & 2.32 \\
Av Ann dom DSM $(T W h / y)$ & 1.37 & 1.11 & 0.01 & 8.56 & 0.38 & 0.01 \\
\hline
\end{tabular}

The contribution of domestic DSM to annual deficit reduction is shown in Table 6. Deficits are greatest within DECC:Nuc at 22.69TWh/yr, domestic DSM reduces these by 8.56TWh/yr. This level of domestic DSM is not practical in maintaining reliability of supply. TP:TF exhibits the smallest annual deficits of $0.01 T W h / y r$, which are completely removed by domestic DSM. When DSM is required, spare generating capacity within the 2 hour window is not always sufficient to enable DSM, resulting in instances where DSM is unfeasible or only able to partially reduce the deficit. These periods are cause for concern in maintaining reliability of supply. Whilst DSM aids balancing in all scenarios, further generation capacity or reduced demand is required in all but $T P: T F$.

\section{Results and analysis}

All the scenarios achieve an emission intensity reduction of $\geq 80 \%$ relative to 1990 levels and full life-cycle analysis (LCA) values have been utilised in determining the emission intensity of the electricity system. Details on method can be found in Quiggin [31]).

\subsection{Non-dispatchable supply}

Figure 11 indicates the annual generation from each non-dispatchable renewable technology; nuclear, CHP and offshore wind create the largest annualised inter-scenario generation divergences.

Figure 12(a-f) illustrates hourly generation for non-dispatchable generators in January, based on 2011 weather data. Wind generation exhibits distinct maximums and minimums, greater wind generation capacity exacerbates fluctuations in non-dispatchable supply such as in TP:CC, TP:MR and $D E C C$ :Renew. For instance DECC:Renew exhibits fluctuations at (40.2 \pm 


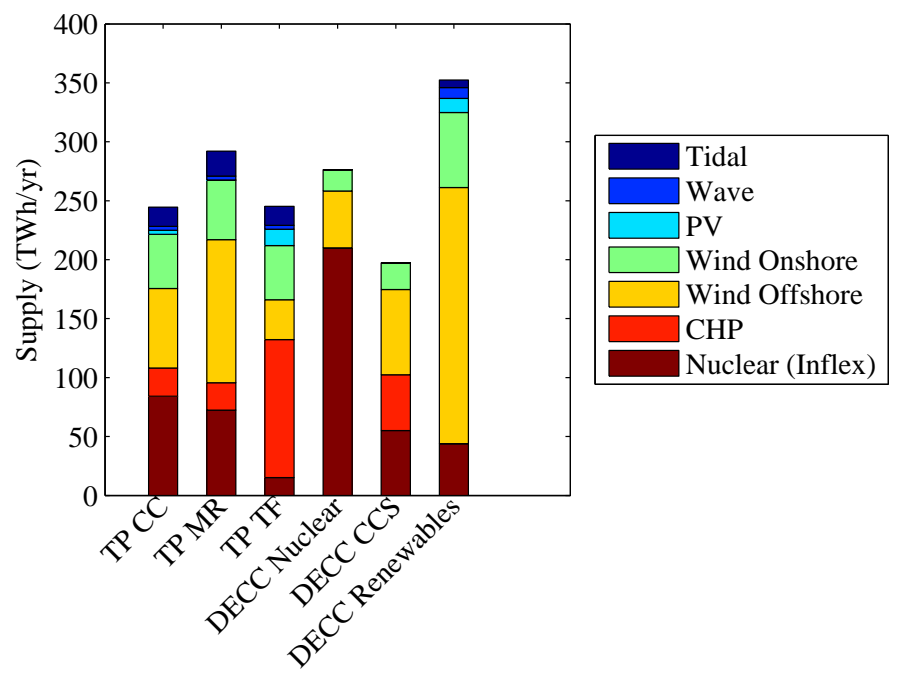

Figure 11: Average annual non-dispatchable supply for each scenario across the eleven years modelled using the scenario projections of space heating.

15.8) $G W$, which includes $\sim 82 G W$ of onshore and offshore wind generators. A distinct break in this pattern is observable in TP:TF (Figure 12(c)), due to $52.5 G W$ of $\mathrm{CHP}$ following heating demands, resulting in a diurnal variation of morning and evening peaks. This generation profile is of greater balancing utility, as national electrical demands follow a similar pattern. DECC:Nuc exhibits the smallest fluctuations in non-dispatchable supply (Figure 12(d)), with a standard deviation $\sim 11.5 \%$ of the mean value, $(31.5 \pm 3.6) G W$. Increased variation in non-dispatchable generation is important, as combined with increased demand variation due to heat electrification, has the potential to compound balancing difficulties. In $T P: T F$, the increased nondispatchable variation is highly correlated to heating demands which are the driver of increased demand variation. 


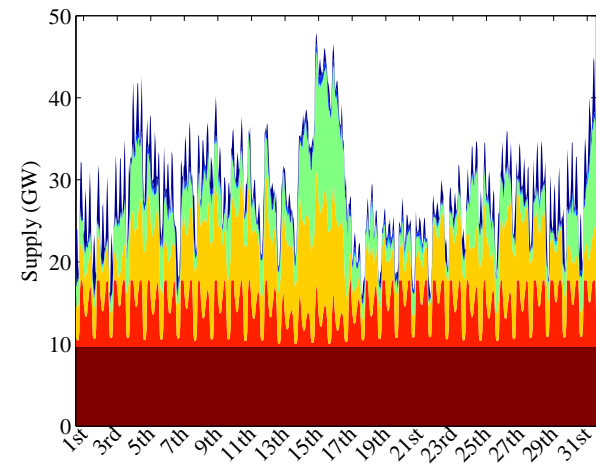

(a) TP Central Coordination.

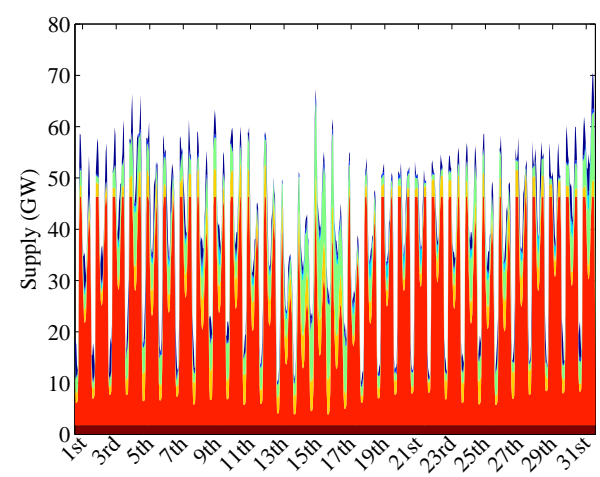

(c) TP Thousand Flowers.

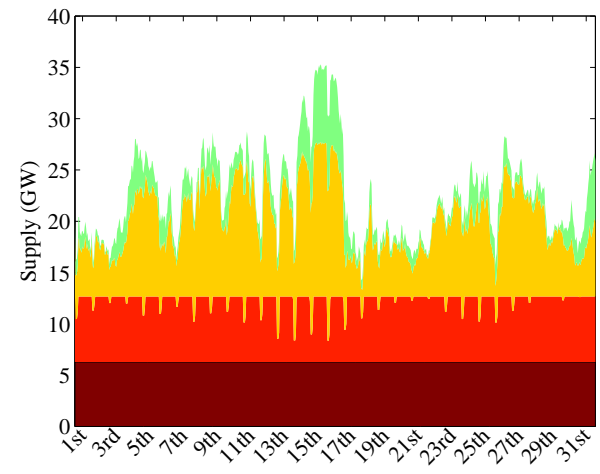

(e) DECC CCS.

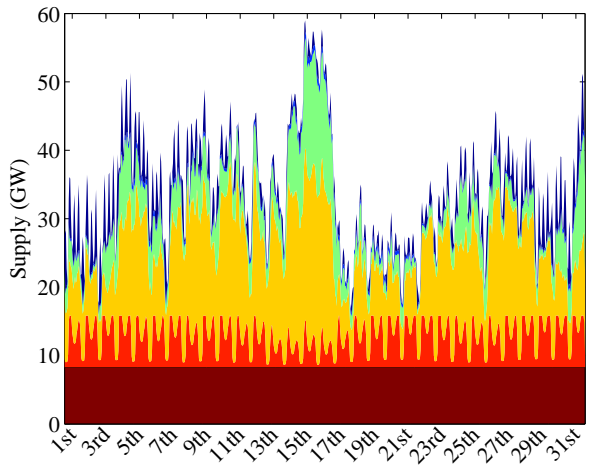

(b) TP Market Rules.

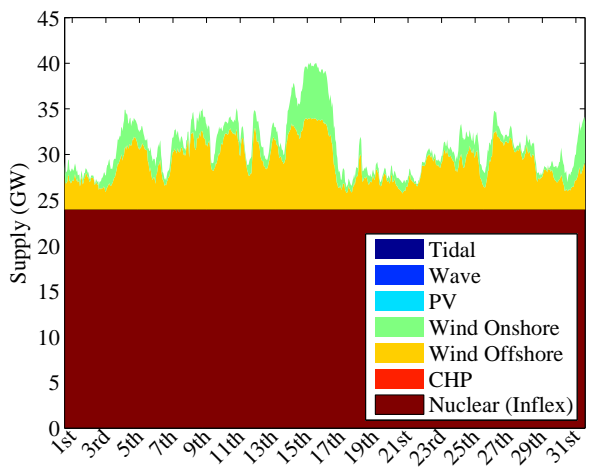

(d) DECC Nuclear.

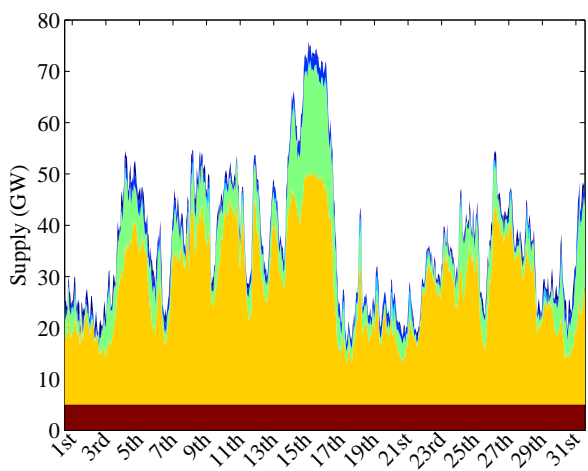

(f) DECC Renewables.

Figure 12: Non-dispatchable supply under various scenarios in January, based on 2011 data. 


\subsection{National demands}

Figure 13 shows mean annual demands over 11 years. Heat pump demand represents $\sim 17.3 \%$ of total demand averaged across the 6 scenarios. $D E C C: N u c$ exhibits the largest share of demand originating from heat pumps at $27.6 \%$ and $T P: T F$ the lowest at $5.7 \%$. TP:TF exhibits significantly lower annual demands due, in part, to lower traditional electricity demand and significantly lower heat pump demand; projecting only $24.5 \%$ of heat to be delivered by heat pumps. This compares to an average of $75.9 \%$ across the five other scenarios. DECC:Renew manages to keep heat pump demand at an average of $73.1 T W h / y r$ even though $90 \%$ of heat is delivered by heat pumps, achieved by reducing heat demand by $44 \%$ with the domestic sector targeted to deliver a $60.4 \%$ reduction.

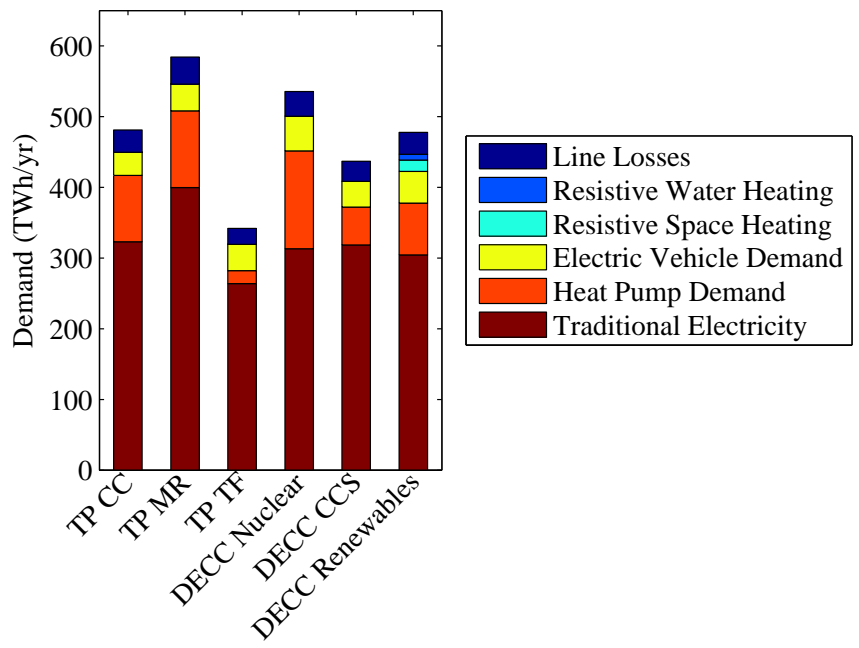

Figure 13: Mean scenario demands using heating demands forecast in the scenarios over 11 years of data (2001:2011).

The importance of heat electrification and reductions in heating demands are illustrated in Table 7 , which shows total electrical peak demands under 2001 data. TP:TF peak demand is $59.4 G W$ which is within historic levels of $56-60 G W$. The high heat pump heat electrification within DECC:Nuc and DECC:Renew ( $88 \%$ and $90 \%$ respectively) drives up peak demand, but the lower heating demands of DECC:Renew reduces the peak from $118.5 G W$ to $90.3 G W$; a difference of $\sim 30 G W$. 
Table 7: Scenario peak total demand and heat pump metrics (based on 2001 data). TP:CC TP:MR TP:TF DECC:Nuc DECC:CCS DECC:Renew

\begin{tabular}{lcccccc}
\hline$\%($ Ann heat) & -19.7 & -13.1 & -35.5 & +4.5 & -15.7 & -44.0 \\
$\%$ Heat supplied by & & & & & & \\
a) resistive heating & 0.01 & 0.01 & 0.01 & 0 & 0 & 10 \\
b) heat pumps & 76.2 & 77.1 & 24.5 & 88.0 & 48.0 & 90.0 \\
Heat Pump COP & 2.65 & 2.65 & 3 & 2.85 & 3.23 & 2.94 \\
Peak $(G W)$ & 101.5 & 119.1 & 59.4 & 118.5 & 79.6 & 90.3 \\
\hline
\end{tabular}

\subsection{National demand profiles}

Figure 14(a-f) shows each scenarios hourly average national daily demand profile during January/February weekdays of; traditional electricity, heat pump demand, electric vehicle demand and resistive heating. As is the case with current national electrical demand, the scenario traditional electricity demand peaks in the early evening, the profile shape resembling current demand profiles. The total national demand profile changes considerably with the higher morning electrified heating demand, resulting in national demand exhibiting two distinct peaks. This effect is distinctive when observing the differences between TP:TF and DECC:Nuc scenarios. The lower heat electrification and greater targeted reductions within TP:TF contrasts to the high heat electrification and small increase in demand with DECC:Nuc (see Table 7), this results in significant demand profile adaptations seen in Figure 14(c), compared to Figure 14(d). The morning peak now exceeds the evening peak in $D E C C: N u c$, whereas the TP:TF profile retains similarity to historic demand profiles. The dominant change to total electrical scenario demand, relative to historic patterns, is the inclusion of the morning peak demand, equivalent in magnitude to the evening peak demand. This results in increased variability, with peak demands greater than historic levels. Across the scenarios the morning peak period is $8-9 \mathrm{am}$ and the evening peak period $7-8 p m$. 


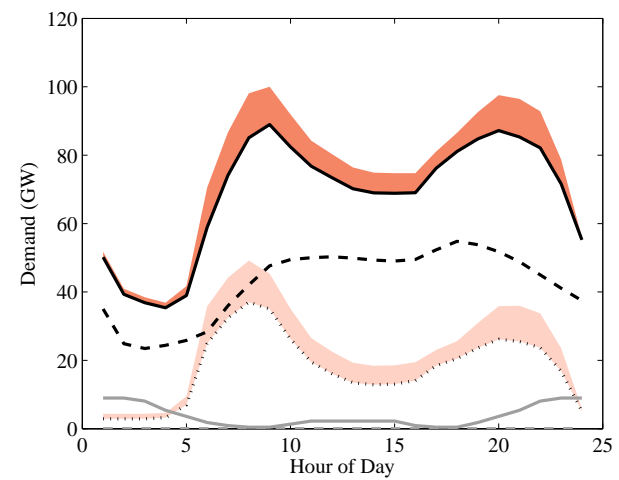

(a) TP Central Coordination.

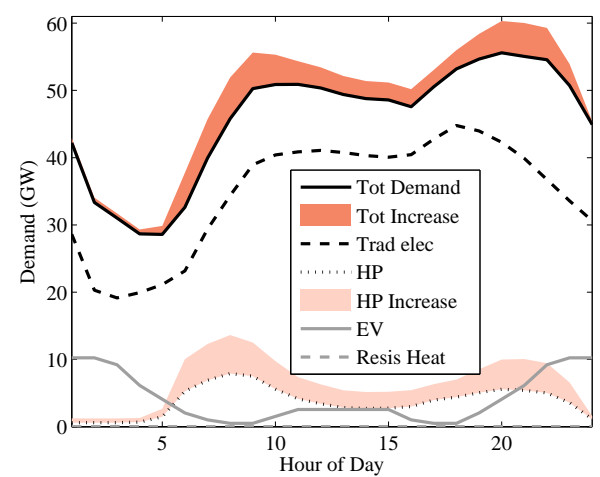

(c) TP Thousand Flowers.

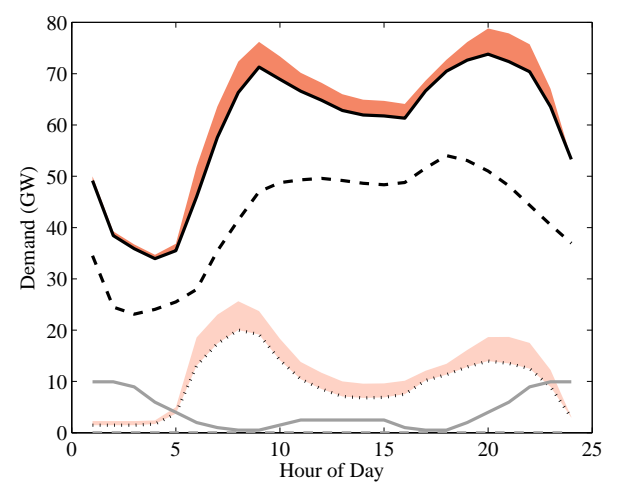

(e) DECC CCS.

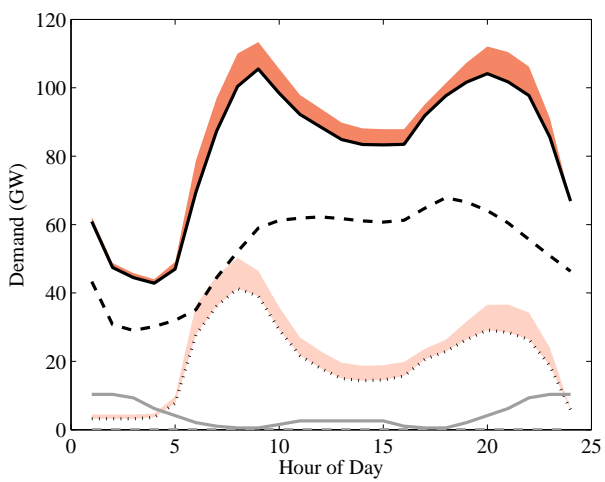

(b) TP Market Rules.

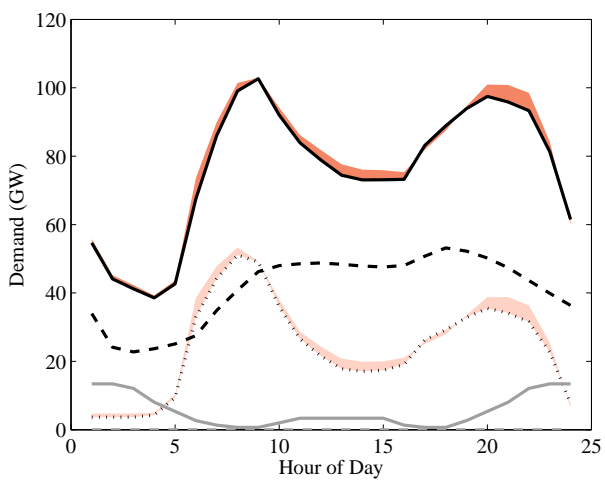

(d) DECC Nuclear.

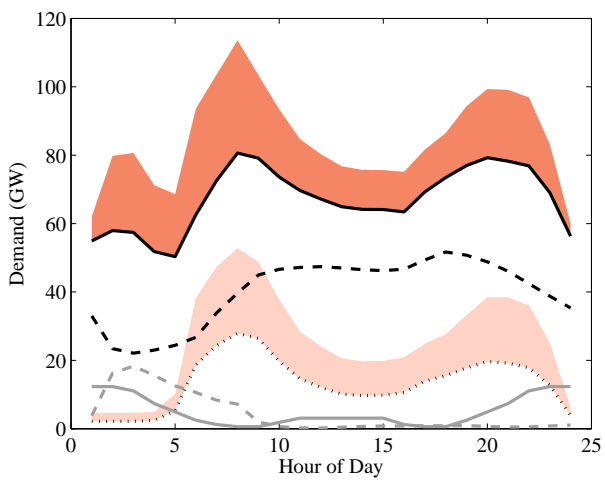

(f) DECC Renewables.

Figure 14: Electricity demand from traditional electricity, heat pumps, electric vehicles and resistive heating for January/February weekdays through 2050 under various scenarios based on 2001-2011 data. The orange areas represent the increase in demand if heating reduction targets are not met. 


\subsection{Implications of failing to achieve heating reduction targets}

Electrification of heating via heat pumps exceeds $75 \%$ in all but two scenarios. A failure to meet heating reduction targets will have a significant impact on electricity demand and consequently reliability of supply. Figure 14(a-f) illustrates changes in the demand profile during January/February weekdays if heating demand remains at historic levels. Heat pump electrical demand is exaggerated resulting in morning and evening peaks becoming increasingly dominant features: exemplified by DECC:Renew which assumes high heat pump electrification, ambitious reduction targets and that $10 \%$ of heat is delivered by resistive heating. Both TP:CC and DECC:Renew scenarios, peak demand becomes dominated by heat pumps rather than the traditional electricity demand, which reinforces the double diurnal demand peaks.

National demand between 2001 and 2011 peaks between $56-60 G W$ with a mean hourly demand of $37.6 G W$ with $\sigma=7.7 G W$. Table 8 gives the $\mu$, $\sigma$ and peak demands for the scenarios for two cases: where heat demand reduction targets are achieved: and where heat demand remains at historic levels. TP:TF is the only scenario where the spread of demand relative to the mean does not increase significantly above historic levels. As can be seen in Table 8, failing to meet heating reduction targets significantly increases the variability and peak demands. This effect is greatest within DECC:Renew where peak demand increases by $36.4 \%$. This increased variation is due to morning and evening heat pump peak demands, such that the average total peak demand across the scenarios increases by $15.3 \%$.

Table 8: Scenario mean, standard deviation and peak demand. heating reduction targets met : historic heating demands. Across all eleven years of data - all in GW.

\begin{tabular}{lcccccccccc} 
& Hist & TP:CC & TP:MR & TP:TF & DECC:Nuc & DECC:CCS & DECC:Renew \\
\hline$\mu$ & 37.6 & $54.9: 57.9$ & $66.6: 68.6$ & $39: 40.6$ & $61.1: 60.4$ & 49.9 & $: 51.1$ & $54.5: 63.9$ \\
$\sigma$ & 7.7 & $15.9: 19.6$ & $18.6: 21.4$ & $8: 9.2$ & $18.2: 19.8$ & $11.7: 13.2$ & $11.9: 19.9$ \\
peak & 59.6 & $116.8: 139.5$ & $137: 154.5$ & $65.3: 74.1$ & 135.7 & $: 144.4$ & 89.9 & $: 100$ & 103.5 & $: 162.6$ \\
\hline
\end{tabular}

\subsection{Reliability of supply}

Assuming space heating reduction targets are met, January and February weekdays pose a significantly greater challenge in maintaining supply-demand 
balance than other periods of the year. Figure 15 shows the average supplydemand imbalance after all balancing mechanisms and dispatchable generators have been deployed, during January and February weekdays, alongside domestic DSM and the imbalance post domestic DSM. DECC:Renew (Figure 15(f)) exhibits continual small deficits, peaking at $\sim 0.9 G W$, the result of which is there being no spare capacity, and hence no possibility of shifting demand. Without an increase in dispatchable generation capacity, a reduction in heating demand or reduced heating electrification, this scenario, along with $D E C C: N u c$, is not viable without regular blackouts or brownouts.

TP:TF (Figure 15(c)) demonstrates almost non-existent deficit periods, with surplus periods in the early morning. For TP:CC, TP:MR and DECC:CCS (Figure $15(\mathrm{a}-\mathrm{b} \& \mathrm{e})$ ) the pattern of deficits occurring during morning and evening peak demand periods can be seen. Domestic DSM contributions are, on average, not able to fully reduce deficits. Taking $D E C C: C C S$ for example (Figure 15(e)), the average post DSM deficits are relatively small, peaking at $1.4 G W$ during the evening. Domestic DSM is capable of reducing the deficit to an average of $0.35 \mathrm{GW}$. Considering all balancing mechanisms (including domestic DSM) have been deployed, this deficit, although small, represents a significant problem if blackouts and brownouts are to be avoided.

The inability of DSM to reduce these deficits further, is a result of insufficient spare capacity within the two hour window either side of the deficit period. Figure 15 highlights an important point: that whilst domestic DSM can help to achieve greater reliability of supply, these scenarios will not provide a reliable supply of electricity.

In order to ascertain the diurnal dynamics of deficits, beyond the average values of Figure 15, probability distributions are plotted for Jan/Feb weekdays in Figure 16(a-f). These are the probability of deficits of varying magnitude, prior to domestic DSM based on the 11 years of data in the model. Of note is the magnitude of deficits under DECC:Nuc and the lack of deficits occurring under TP:TF; note the different z-scales in these plots. The morning and evening peak period pattern of deficits is evident all scenarios (Figure 16(a, b, d \& e)), accept for DECC:Renew (Figure 16(f)). This feature is exacerbated due to the levels of electrified heating. The most important period is the evening, when the duration of peak demand is longer. In the mornings, the peak demand periods are shorter, resulting in DSM being able to shift demand away from acute deficit periods.

DECC:Renew exhibits distinctly different deficit patterns, occurring throughout the day at a low level, generally below $5 G W$. This results in a challenging 


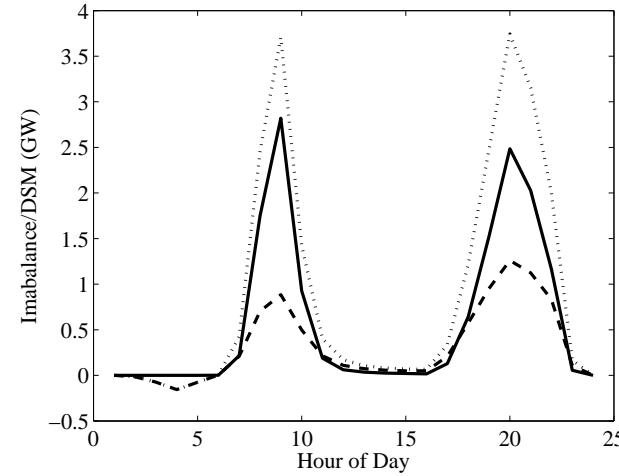

(a) TP Central Coordination.

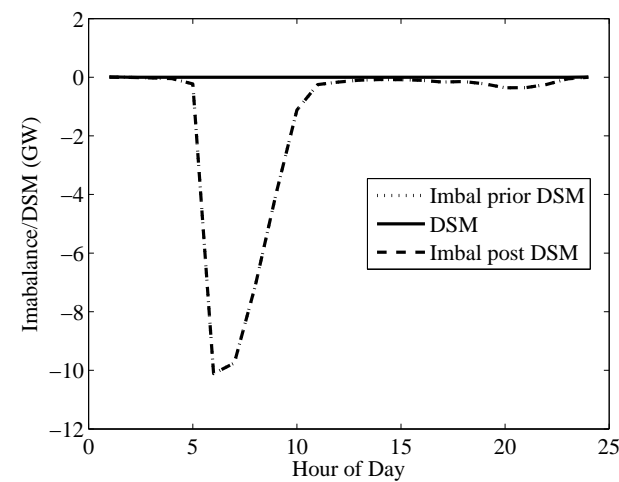

(c) TP Thousand Flowers.

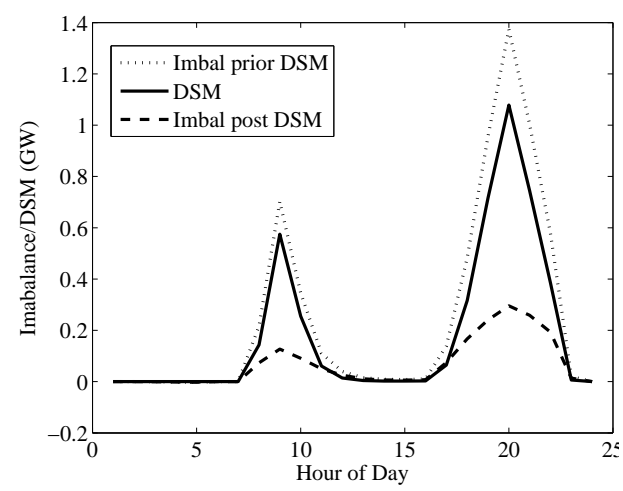

(e) DECC CCS.

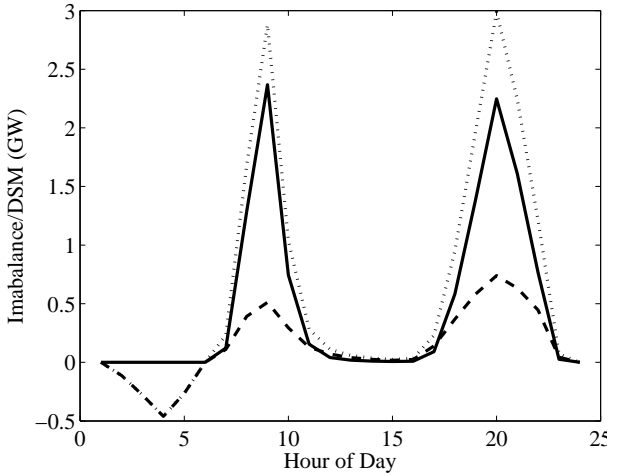

(b) TP Market Rules.

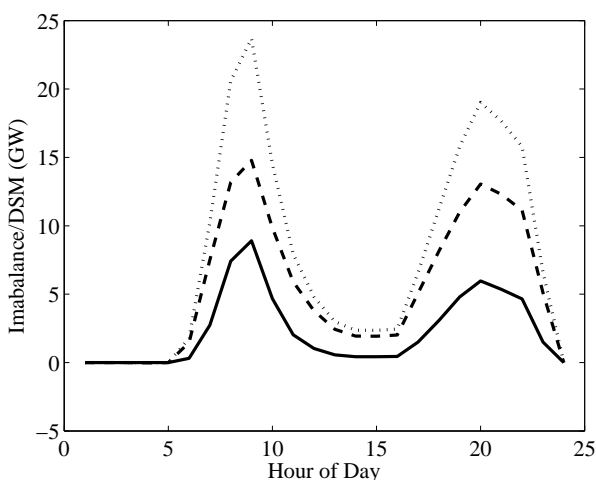

(d) DECC Nuclear.

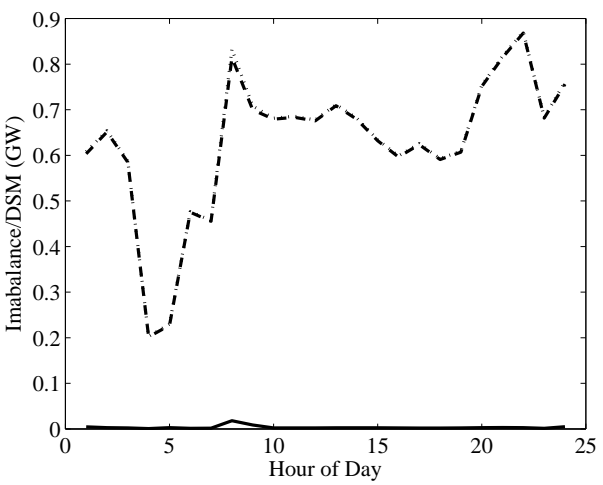

(f) DECC Renewables.

Figure 15: Average imbalance during Jan/Feb weekdays, domestic DSM required and imbalance post DSM participation during 2050 for each scenario under all eleven years of SHED data. Negative values indicate a surplus rather than a deficit. 


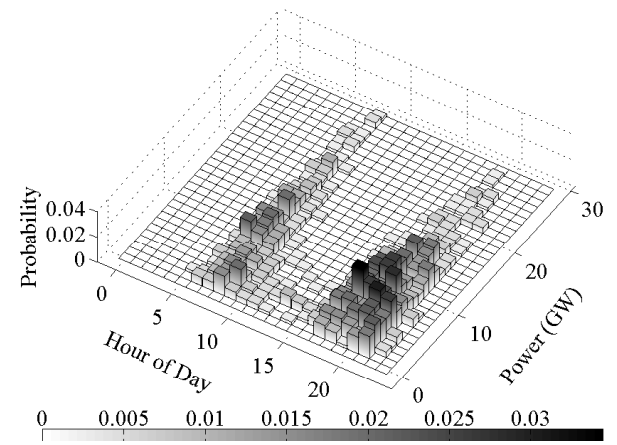

(a) TP Central Coordination.

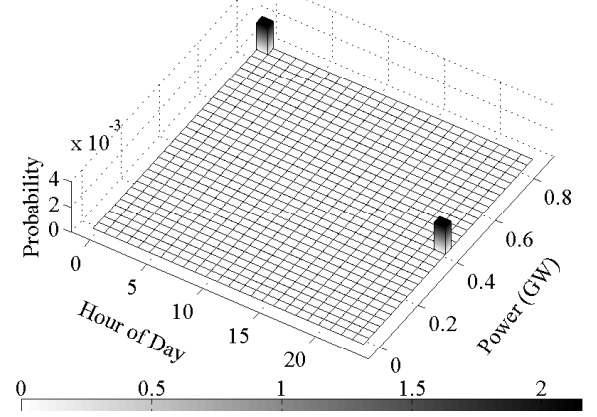

(c) TP Thousand Flowers.

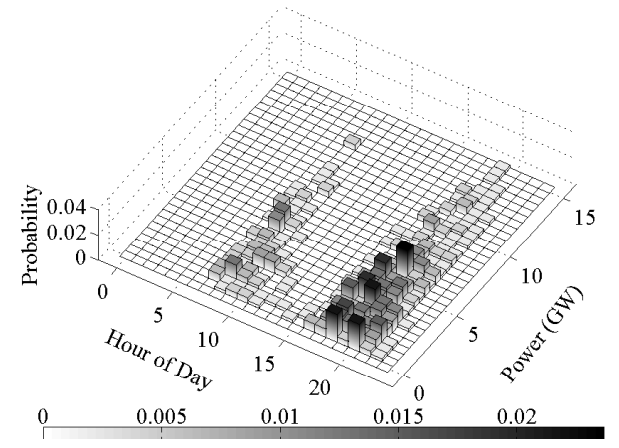

(e) DECC CCS.

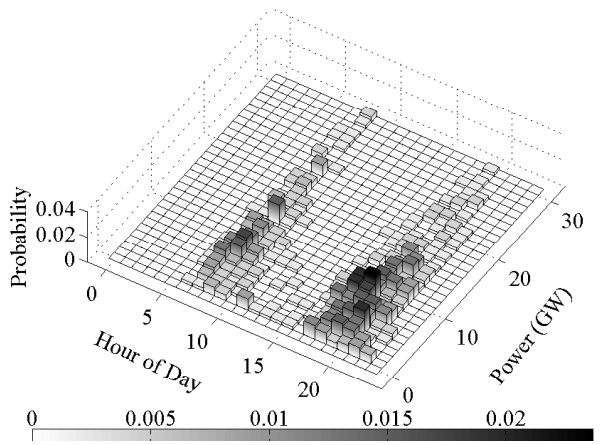

(b) TP Market Rules.

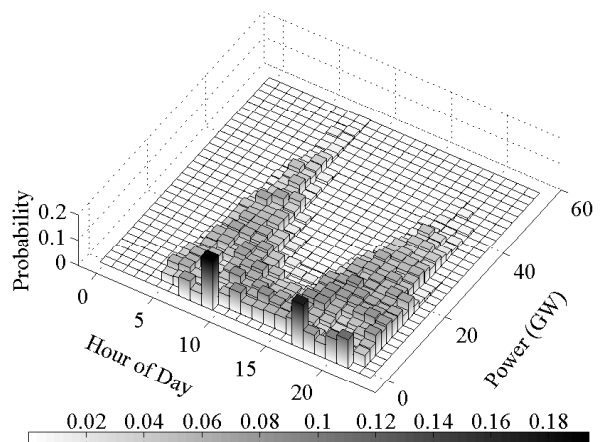

(d) DECC Nuclear.

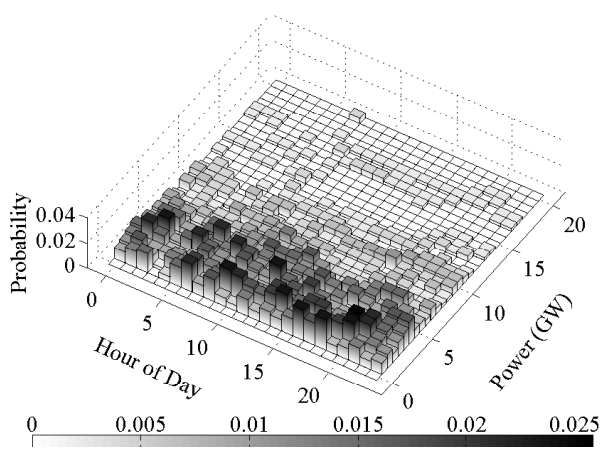

(f) DECC Renewables.

Figure 16: Probability distribution of deficits prior to domestic DSM Jan/Feb weekdays.

situation, DSM is not possible as spare capacity is not available either side of a deficit. This is due to the combination of a high degree of electrification, a large market share of renewables, and only $20 G W$ of dispatchable generators. 


\section{Discussion}

The SHED model has been developed and used here to explore six published future energy scenarios. It builds on the methodology used by the FESA model but differs in three significant ways:

- it makes no assumption about the ability to balance demand through demand-side management;

- rather than using an idealised assumption about constant energy consumption associated with the ideal performance of heat pumps supplying space heating demand, it utilises a more likely heating profile that is more characteristic of the morning evening heating periods that is typical today; and,

- it uses data gathered over at 11 years in order to generate probabilistic analysis from the discrete modelling approach, in addition the temperature data used to drive heating models is based on measurements from an number of weather stations around the UK rather than weighting the measurements from an individual location as done in FESA.

In order to asses the viability of the six selected scenarios in regards to reliability of supply, a number of modelling assumptions were made. Heat pump heating electrification is a principle driver of national electrical demand variation, relative to historic patterns. It is therefore worth considering those modelling assumptions that relate to heat electrification.

\subsection{Sub-daily heating demands and profiles}

Although assumptions have been made regarding sub-daily modelling of heating demands, the work presented here advances the current knowledge of sub-daily heating demands. The heating profile from Woods and Dickson [28] was utilised to model hourly domestic space heating demands, this profile originates from a district heating scheme of a social housing complex and was used because aggregate sub-daily gas demand data is not readily available for the UK and the modelling developed here required a separation of domestic and non-domestic demand. The profile used, is however, similar to that reported in work by Sansom and Strbac [42] and Yao and Steemers [43]. Further work would benefit from further investigation of robust representative aggregate domestic heating profiles. 


\subsection{Implications of heating profiles on heat pump functionality}

Heat pumps are not typically expected to follow variable, peaky demand patterns [44; 45], as is the case in the model described here. Strbac et al. [46] investigated the impacts of aggregated household heating demands, supplied by heat pumps, on peak electrical demands in 21 households with Grade A insulation. In the case where there is no heat storage or additional heating delivery technology (such as resistive heating), the aggregate electrical demands of heat pumps have a daily diurnal cycle similar to the Woods and Dickson [28] profile. It should be noted that in SHED the unrestricted profile is applied to model electrified heating without DSM. The DSM algorithm used allows heating demand to be shifted forward in time via storage, if there is sufficient spare capacity or surplus renewable supply to satisfy that demand.

The biggest change in national electrical demand is brought about by significant use of heat pumps. If the ideal future of a constant heat demand is not realised and the resulting demand is closer to the unrestricted profile explored here, it will result in increased variation, with two equally important peaks in the 24 hour cycle.

The results demonstrate the importance of meeting the demand reduction targets that underpin the scenarios. In all cases, failing to meeting the demand reduction targets results in greater variability in the demand, which increases the difficulties in mitigating deficit periods through demand side management. This is particularly sensitive for scenarios that have a high proportion of non-dispatchale supply, nuclear power for example, where increased demand and greater variation compounds balancing issues.

All but one scenario demonstrated serious supply deficit issues on winter days when heating demand is high due to the envisioned proportions of electrified space heating. The Transition pathways: Thousand Flowers scenario contains a significant proportion of CHP generation, which offsets heating demand and simultaneously generates electricity during the highest demand periods. These findings mirror those undertaken in Denmark, where the conclusions were to combine CHP with large scale heat pumps in order to meet the energy demands during the coldest seasons $[12 ; 13]$ and are comparable to studies in Lithuania [17]. 


\section{Conclusions}

The paper presented a new model for estimating supply deficits of the future UK electrical energy system. Grounded on the principles of FESA, the weather data the model is based on has been improved significantly and critically, the new model does not make assumptions about the role of demand side management, but rather models this in order to evaluate the viability of a particular energy scenario. The paper described the model and then applied it to investigate 6 published scenarios that represent a range of potential energy system futures for the UK. It was demonstrated that:

- hourly modelling is essential to investigate the influence of electric heating on national energy strategies;

- electric heating has a significant influence on electricity peak load;

- failure to achieve significant demand reduction will increase demand and its variation, compounding the balancing issue;

- the DECC 'renewables' and 'nuclear' scenarios are not viable due to the frequency of unservicable deficits; and,

- CHP and district heating may be a viable solution, which is supported by previous research in the same field $[12 ; 13]$.

$T P: T F$ is the one scenario where very few deficits exist, mainly because space and water heating are not significantly electrified. Instead, high hourly heating demands result in surplus power generation, an inversion of the problems of the other scenarios. Although delivering the $52.5 \mathrm{GW}$ of decentralised CHP capacity is challenging target for the UK, this should be considered in the context of previous research $[12 ; 13]$ in which the role of CHP and district heating in combination with heat pumps, has been demonstrated as a potentially viable approach to enable highly decarbonised systems to deliver a reliable energy supply.

The results indicate that electrification of heating combined with decarbonisation of the electricity system, are not simple substitutions for existing energy forms. If electricity is the form of energy through which a secure and clean energy future is to be delivered, then heating demand reduction must be achieved alongside heat electrification, with domestic DSM playing 
a significant balancing role.

\section{Acknowledgements}

This research was made possible by Engineering and Physical Sciences Research Council (EPSRC) support for the London-Loughborough Centre for Doctoral Research in Energy Demand (grant EP/H009612/1).

\section{References}

[1] T. J. Foxon, P. J. Pearson, S. Arapostathis, A. Carlsson-Hyslop, J. Thornton, Branching points for transition pathways: assessing responses of actors to challenges on pathways to a low carbon future, Energy Policy 52 (2013) 146-158.

[2] T. J. Foxon, G. P. Hammond, P. J. G. Pearson, Developing transition pathways for a low carbon electricity system in the UK, Technological Forecasting and Social Change 77 (8) (2010) 1203-1213. doi:10.1016/j.techfore.2010.04.002.

URL http://dx.doi.org/10.1016/j.techfore.2010.04.002

[3] M. Barnacle, E. Robertson, S. Galloway, J. Barton, G. Ault, Modelling generation and infrastructure requirements for transition pathways, Energy Policy 52 (2013) 60-75. doi:10.1016/j.enpol.2012.04.031.

[4] Department for Energy and Climate Change, Smarter Grids: The Opportunity, Tech. Rep. December (2009).

[5] Department of Energy and Climate Change, 2050 Pathways Analysis, Tech. Rep. July (2010).

[6] T. J. Foxon, Transition Pathways for a Low Carbon Electricity Future: Exploring roles of actors, governance and branching points, East (November).

[7] J. Speirs, R. Gross, S. Deshmukh, P. Heptonstall, M. Leach, J. Torriti, Heat delivery in a low carbon economy, Tech. Rep. Opsi 2008 (2010).

[8] I. G. Wilson, A. J. Rennie, Y. Ding, P. C. Eames, P. J. Hall, N. J. Kelly, Historical daily gas and electrical energy flows through Great Britain's transmission networks and the decarbonisation of domestic heat, Energy Policydoi:10.1016/j.enpol.2013.05.110. 
[9] H. Lund, Renewable energy strategies for sustainable development, Energy 32 (6) (2007) 912-919. doi:10.1016/j.energy.2006.10.017.

[10] H. Lund, B. Mathiesen, Energy system analysis of $100 \%$ renewable energy systemsThe case of Denmark in years 2030 and 2050, Energy 34 (5) (2009) 524-531. doi:10.1016/j.energy.2008.04.003.

[11] H. Lund, Large-scale integration of optimal combinations of PV, wind and wave power into the electricity supply, Renewable Energy 31 (4) (2006) 503-515. doi:10.1016/j.renene.2005.04.008.

[12] H. Lund, Large-scale integration of wind power into different energy systems, Energy $30 \quad$ (13) (2005) 2402-2412. doi:10.1016/j.energy.2004.11.001.

URL http://linkinghub.elsevier.com/retrieve/pii/S0360544204004736

[13] H. Lund, E. Münster, Modelling of energy systems with a high percentage of CHP and wind power, Renewable Energy 28 (14) (2003) 2179-2193. doi:10.1016/S0960-1481(03)00125-3.

[14] H. Lund, A. Marszal, P. Heiselberg, Zero energy buildings and mismatch compensation factors, Energy and Buildings 43 (7) (2011) 1646-1654. doi:10.1016/j.enbuild.2011.03.006.

[15] W. Liu, H. Lund, B. V. Mathiesen, Large-scale integration of wind power into the existing Chinese energy system, Energy 36 (8) (2011) 47534760. doi:10.1016/j.energy.2011.05.007.

[16] H. Lund, F. Hvelplund, K. Ingermann, G. Kask, Estonian energy system Proposals for the implementation of a cogeneration strategy 28 (2000) $1-8$.

[17] H. Lund, G. Šiupšinskas, V. Martinaitis, Implementation strategy for small CHP-plants in a competitive market: the case of Lithuania, Applied Energy 82 (3) (2005) 214-227. doi:10.1016/j.apenergy.2004.10.013.

[18] D. Connolly, H. Lund, B. Mathiesen, M. Leahy, A review of computer tools for analysing the integration of renewable energy into various energy systems, Applied Energy 87 (4) (2010) 1059-1082. doi:10.1016/j.apenergy.2009.09.026. 
[19] J. Barton, S. Huang, D. Infield, M. Leach, D. Ogunkunle, J. Torriti, M. Thomson, The evolution of electricity demand and the role for demand side participation, in buildings and transport, Energy Policy 52 (2013) 85-102. doi:10.1016/j.enpol.2012.08.040.

[20] R. Kannan, The development and application of a temporal MARKAL energy system model using flexible time slicing, Applied Energy 88 (6) (2011) 2261-2272. doi:10.1016/j.apenergy.2010.12.066.

[21] The NETA Web Site, ELEXON (2013).

URL www. bmreports.com

[22] S. Acha, T. C. Green, N. Shah, Optimal Charging Strategies of Electric Vehicles in the UK Power Market, in: Innovative Smart Grid Technologies (ISGT) IEEE PES, 2011, pp. 1-8.

[23] Department of Energy and Climate Change, DECC 2050 Pathways calculator (2013).

[24] Department of Trade and Industry, New and Renewable Energy: Prospects in the UK for the 21st Century: Supporting Analysis, ETSU R-122, Tech. rep. (1998).

URL www.dti.gov.uk/renewables/publications/pdfs/support.pdf

[25] UK Meteorological Office, MIDAS Land Surface Stations data (1853-current): Available from http://badc.nerc.ac.uk/view/badc.nerc.ac.uk__ATOM__dataent_ukmomidas, NCAS British Atmospheric Data Centre.

URL www.badc.rl.ac.uk/

[26] UK Meteorological Office, Met Office Wave Data, Tech. rep., UK Meteorological Office (2013).

[27] Department for Energy and Climate Change, DECC Statistics, Tech. rep., DECC (2013).

[28] P. Woods, J. Dickson, The contribution CHP can make to energy efficiency in buildings, in: IMechE Seminar, Energy Efficiency in Buildings, 2004. 
[29] D. Parker, T. Legg, C. Folland, A new daily Central England Temperature Series, 1772-1991, Int. J. Clim 12 (1992) 317-342.

[30] W. Kempton, J. Tomić, Vehicle-to-grid power fundamentals: Calculating capacity and net revenue, Journal of Power Sources 144 (1) (2005) 268-279. doi:10.1016/j.jpowsour.2004.12.025.

[31] D. Quiggin, Modelling the expected participation of future smart households in demand side management, within published energy scenarios, Ph.D. thesis, Loughborough University (2014).

URL https://dspace.lboro.ac.uk/2134/16220

[32] Department for the Environment Food and Rural Affairs, Land by agricultural and other uses (2003).

URL defra.gov.uk/environment/statistics/land/lduse.htm

[33] The Office for the Deputy Prime Minister, Generalised Land Use Database Statistics for England (2004).

[34] S. Hsu, Coastal Meteorology (1988).

[35] RE Power Systems, No Title (2013).

URL repower.de/wind-power-solutions/wind-turbines/5m/

[36] D. Mackay, Sustainable Energy without the hot air, 2009.

[37] R. Kirby, L. Shaw, Severn Barrage , UK environmental reappraisal, Tech. Rep. March (2005).

[38] H. Lund, B. Möller, B. Mathiesen, A. Dyrelund, The role of district heating in future renewable energy systems, Energy 35 (3) (2010) 13811390. doi:10.1016/j.energy.2009.11.023.

[39] Department of Energy and Climate Change, Gas Generation Strategy, Tech. Rep. December (2012).

[40] Nuclear Energy Agency OECD, Technical and economic aspects of load following with nuclear power plants, Tech. rep. (2011).

URL oecd-nea.org/ndd/reports/2011/load-following-npp.pdf

[41] Ofgem, Demand side response in the non-domestic sector, Tech. Rep. May (2012). 
[42] R. Sansom, G. Strbac, The impact of future heat demand pathways on the economics of low carbon heating systems, in: BIEE 9TH ACADEMIC CONFERENCE, Oxford, 2012.

[43] R. Yao, K. Steemers, A method of formulating energy load profile for domestic buildings in the UK, Energy and Buildings 37 (6) (2005) 663671. doi:10.1016/j.enbuild.2004.09.007.

[44] P. Boait, A. Stafford, Electrical Load Characteristics Of Domestic Heat Pumps And Scope For Demand Side Management (0125) (2011) 6-9.

[45] EST, Detailed analysis from the first phase of the Energy Saving Trust s heat pump field trial, Tech. Rep. 3 (2012).

[46] G. Strbac, C. K. Gan, M. Aunedi, V. Stanojevic, P. Djapic, J. Dejvises, P. Mancarella, A. Hawkes, D. Pudjianto, D. Openshaw, S. Burns, P. West, D. Brogden, A. Creighton, A. Claxton, Benefits of Advanced Smart Metering for Demand Response based Control of Distribution Networks, Tech. rep. (2010). 